\title{
Examining sensorial interfaces as the stimuli for remote affective communication
}

\author{
by
}

Xinchu Zhang

A thesis submitted to the Faculty of Graduate and Postdoctoral Affairs in partial fulfillment of the requirements for the degree of

\author{
Master of Design \\ in \\ Industrial Design
}

\author{
Carleton University \\ Ottawa, Ontario \\ (C2013, Xinchu Zhang
}




\begin{abstract}
Current communication technologies have a significant role in satisfying social connection and networking, but have not yet been developed to entirely support interpersonal communication, especially in creating and maintaining intimacy and a sense of connection in an intimate relationship, specifically with young adult children and older parents. Under the emerging trend of ubiquitous computing, this research examines the possibility of creating new means for augmenting intimacy in remote affective communication between young adult children and older parents. From a small-targeted group, this exploratory study rooted in family communication activities and family life is exploring the possible themes, cues and artefacts that support family closeness but are missing in conventional communication (audio and video). By generating a group of concepts and new tools for remote family interaction, the findings of this thesis offer insights into new means of communication tools for supporting family connectedness.
\end{abstract}

Key words: Affective communication, remote intimacy, wearable technology, interaction design, sensory enhancement, metaphors 


\section{ACKNOWLEDGMENTS}

I would like to thank my advisor Prof. Lois Frankel at the School of Industrial Design and my co-advisor Prof. Audrey Girouard from the School of Information Technology for their continued support, patience and guidance throughout this process. Thanks for their patient guidance to encourage me refine ideas and countless hours spent reviewing my work. I would not have been able to do the research and achieve learning without their help.

Furthermore, thanks to all the participants for dedicating precious time to this study. They offered valuable information and ideas, which make it possible to explore this research topic. I am very grateful for all the help from Dea Attar, Xiaofeng Yong and Miao Guo. Thanks for assisting me organizing the workshops during the data collection process.

Finally, I would like to thank all my friends, family, and classmates for your encouragement and support to motivate me to accomplish this thesis. I am eternally grateful. 


\section{TABLE OF CONTENTS}

ABSTRACT …............................................................................................................. i

ACKNOWLEDGMENTS................................................................................................. ii

TABLE OF CONTENTS ................................................................................................. iii

LIST OF TABLES ...............................................................................................................

LIST OF FIGURES ................................................................................................. viii

CHAPTER 1. INTRODUCTION ............................................................................ 1

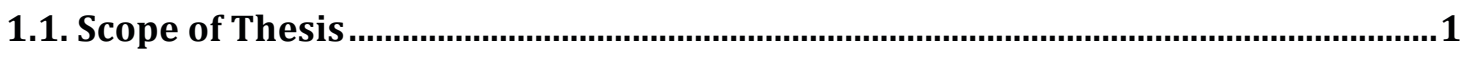

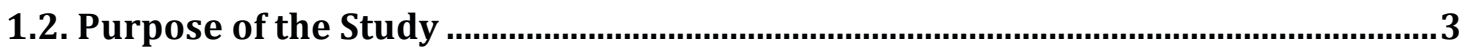

1.3. Research Questions and Hypotheses.....................................................................4

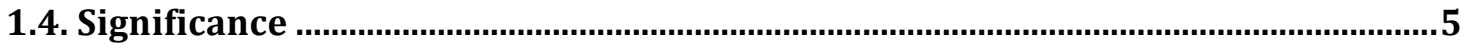

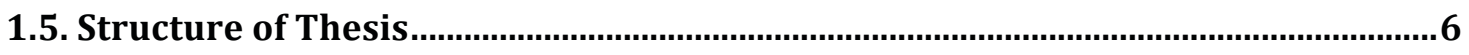

CHAPTER 2: LITERATURE REVIEW

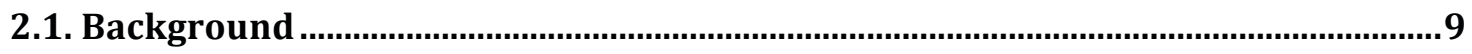

2.1.1. Current Communication Technologies ..........................................................................

2.1.2. Related Studies Targeting Parent-Children Communication...................................... 11

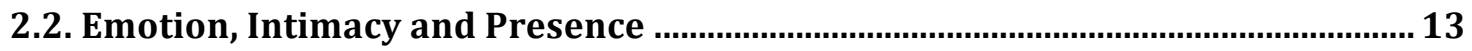

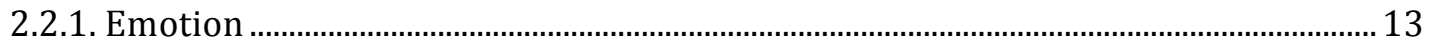

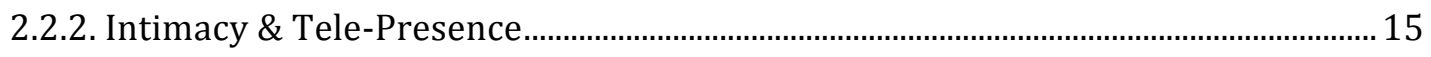

2.3. Cues, Sensory Enhancement and Metaphors ….................................................. 17

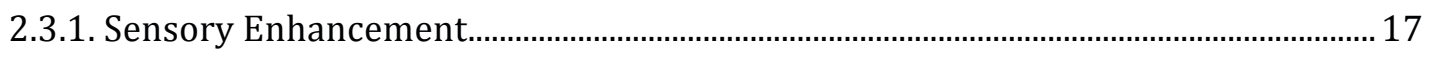

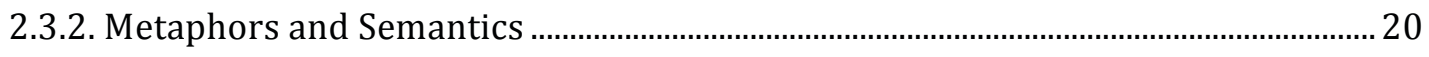




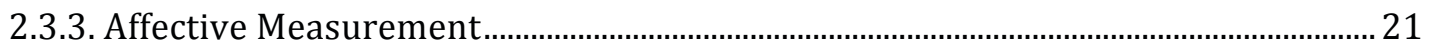

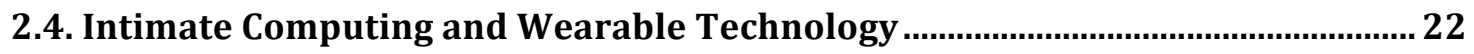

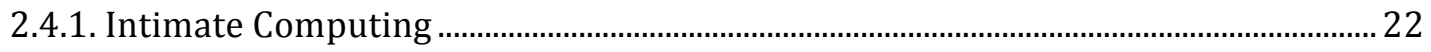

2.4.2. Ubiquitous Computing and Wearable Technology ....................................................... 23

2.4.3. Embedded Techniques and Interfaces............................................................................ 24

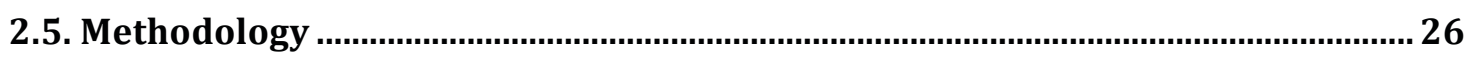

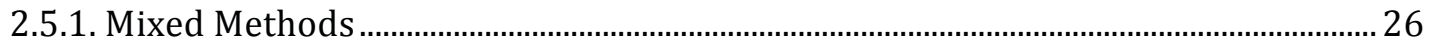

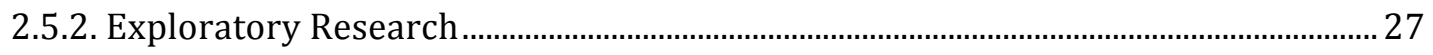

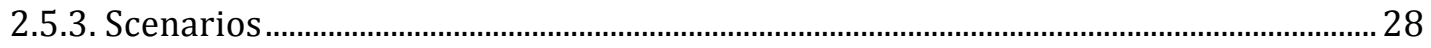

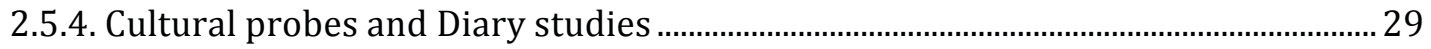

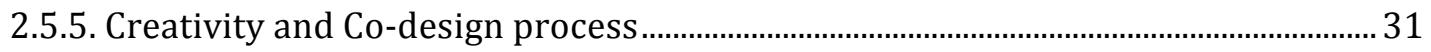

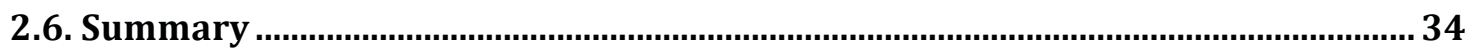

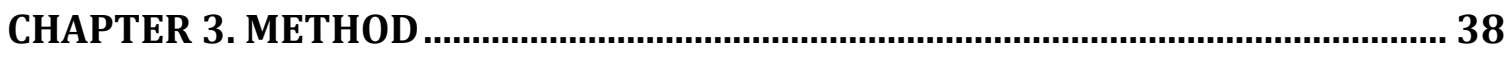

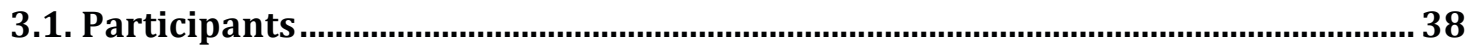

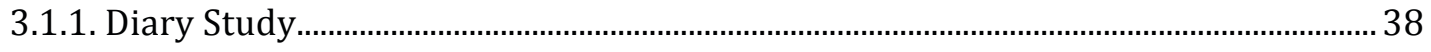

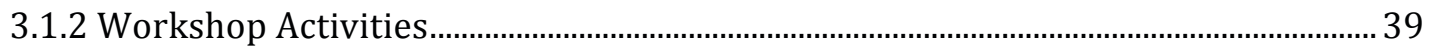

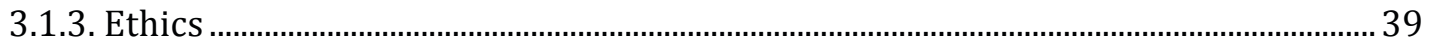

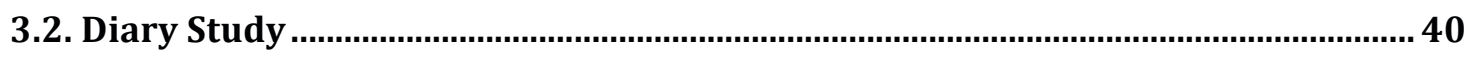

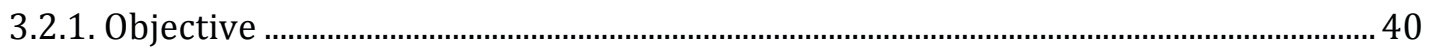

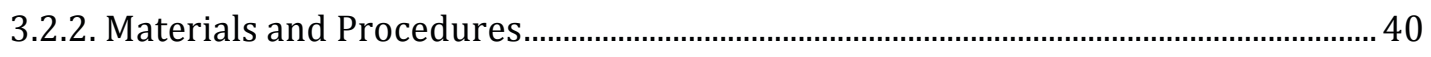

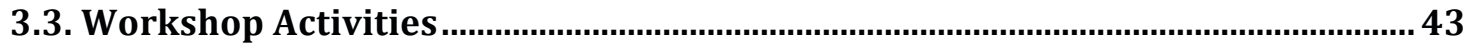

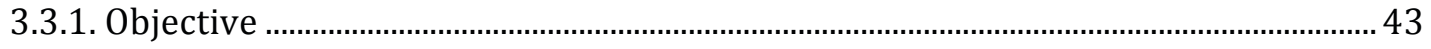

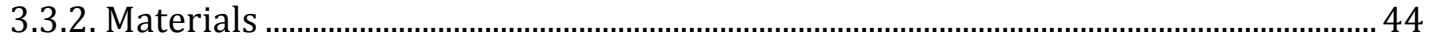

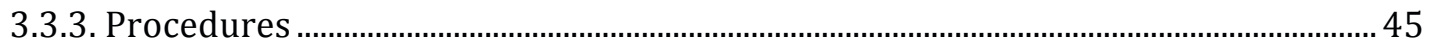

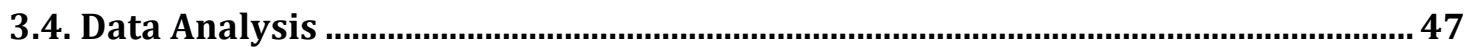


CHAPTER 4. RESULTS

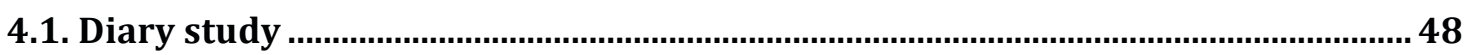

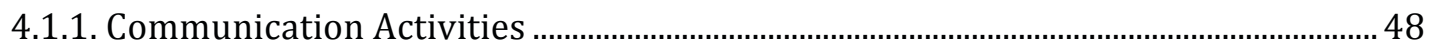

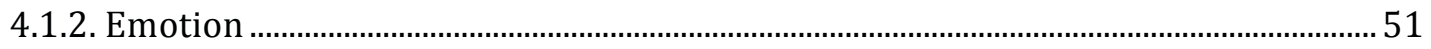

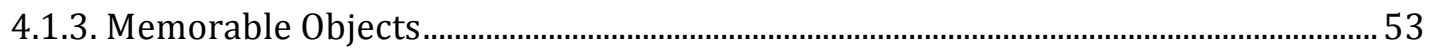

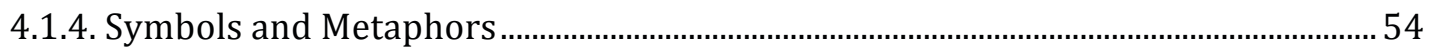

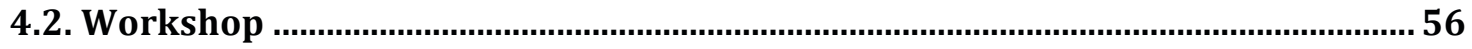

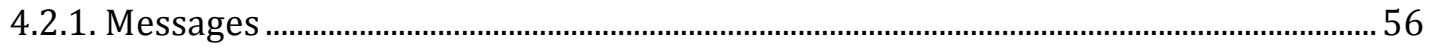

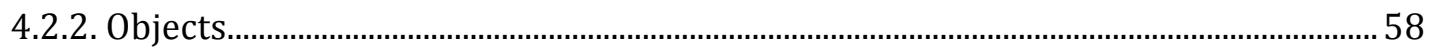

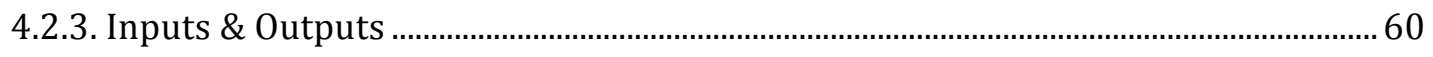

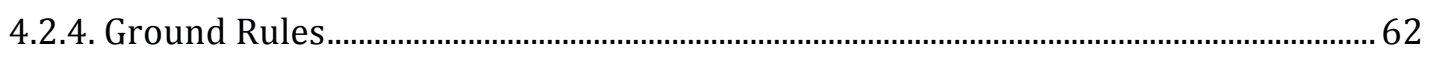

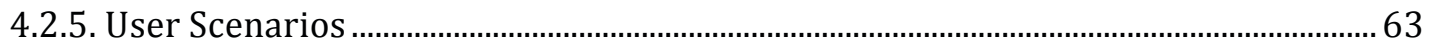

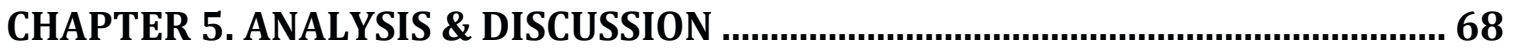

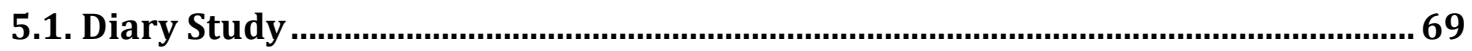

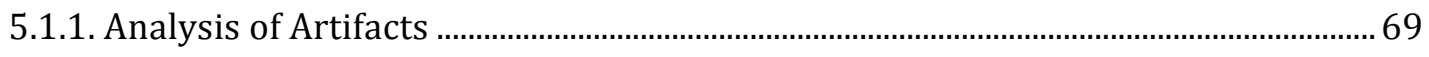

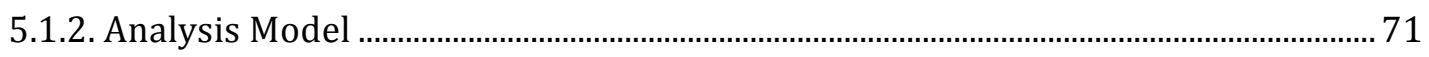

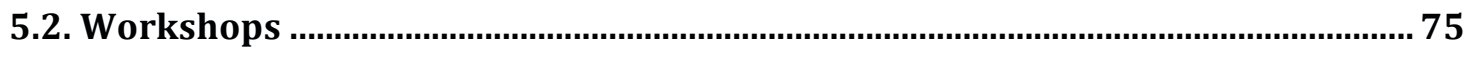

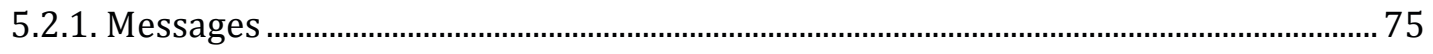

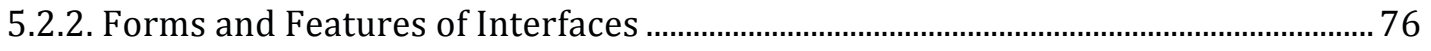

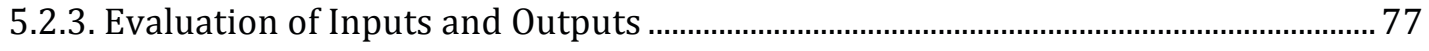

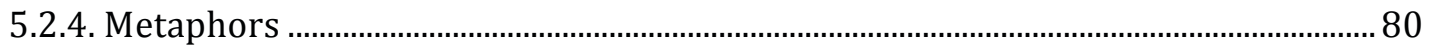

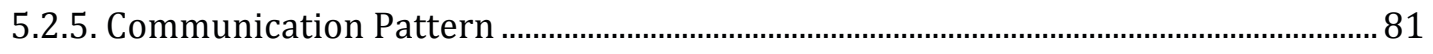

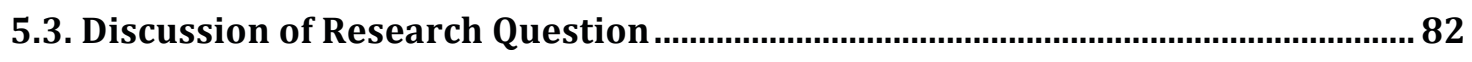

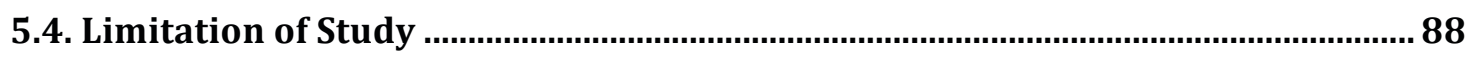




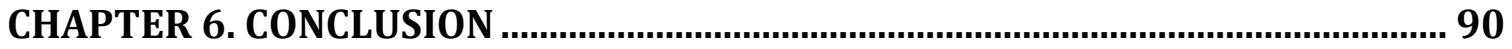

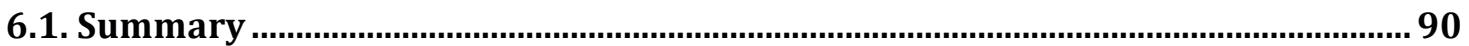

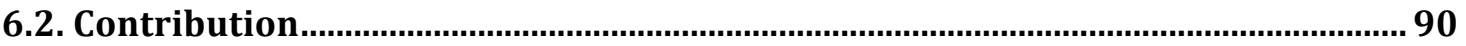

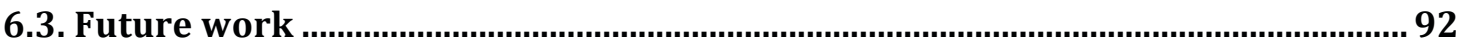

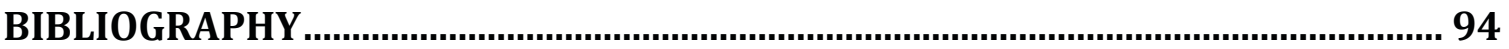

APPENDIX A. Diary study questionnaire …….....................................................100

APPENDIX B. The results of Emotional expressions exercise...............................103

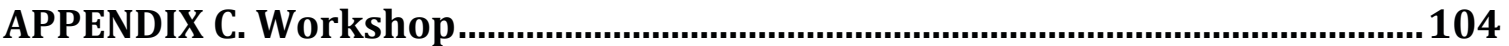

APPENDIX D. Ethics Documentation ..................................................................108 


\section{LIST OF TABLES}

Table 1. Participants' demographics and groupings 39

Table 2. Content of Message \& Object cards 44

Table 3. Comparison of group Parent and group Children for familiarity to technology: 49

Table 4. Assessing participants' feeling about using devices. 50

Table 5. Assessing participants' overall feeling when they communicate 52

Table 6. Interpretations of emoticons from positive to negative 52

Table 7. Participants' interpretation about Concerned, Worried and Speechless signals . 53

Table 8. Memorable Objects collected from parents and children groups 53

Table 9. Categories of Metaphors through the images provided by participants 55

Table 10. The categories generated from card sorting exercise and corresponding three main categories 56

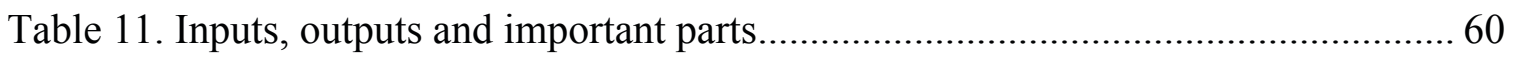

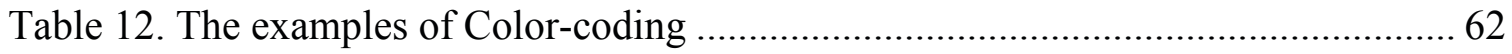

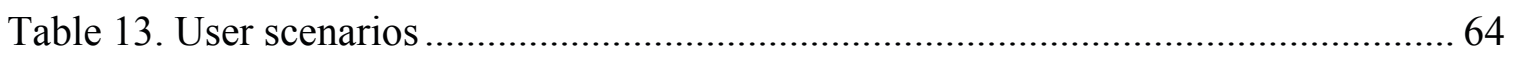

Table 14. Asymmetrical and Symmetrical features of the objects between parents and

children 65

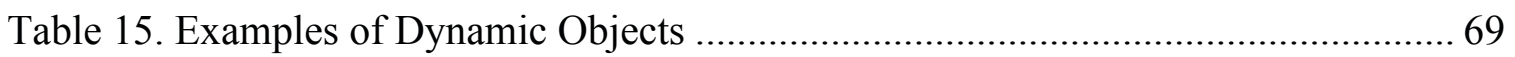

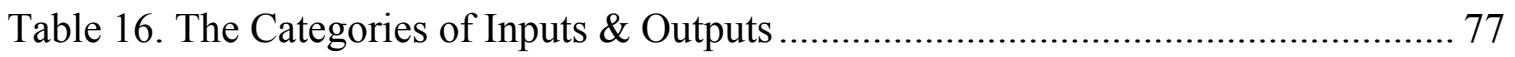

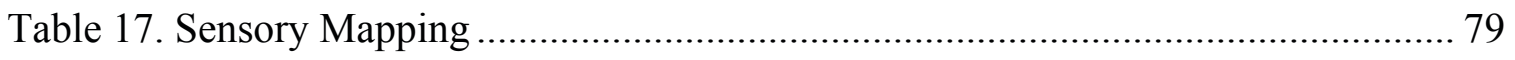

Table 18. The numbers and interpretations of emotional expressions......................... 103 


\section{LIST OF FIGURES}

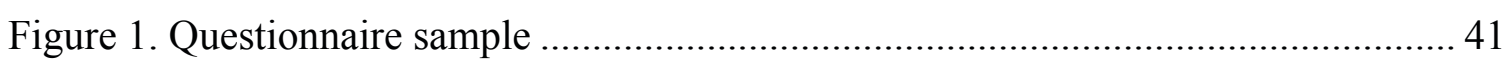

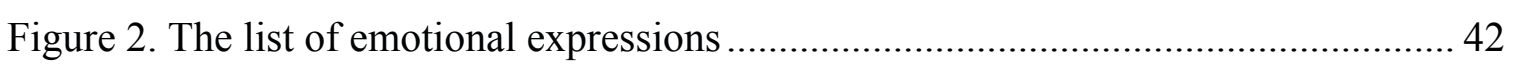

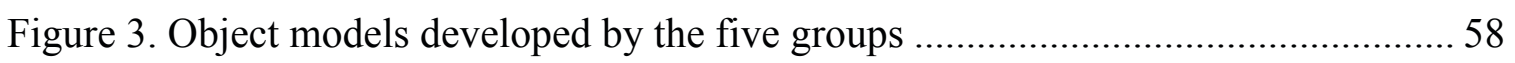

Figure 4. The analysis model: a comparison between conventional tools and memorable

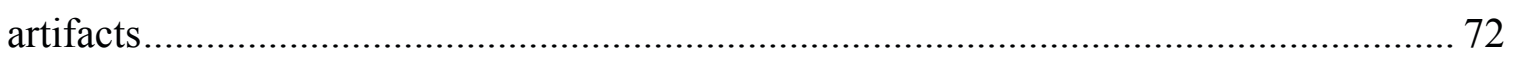

Figure 5. Conceptual models of remote interaction with digital and physical objects ..... 82 


\section{CHAPTER 1. INTRODUCTION}

\subsection{Scope of Thesis}

The dynamics between family members has been affected by the physical separation of young adult children from their parents, which can increase with the growth of age (Kobrin, 1976). This physical separation in different cities due to work, education needs or establishing a new family is such a frequent occurrence that it becomes a social phenomenon (Kobrin, 1976). The first consequence of this voluntary separation is the reduced contact and time families spend together, modifying the dynamic between parents and children, creating a larger disconnect and a loss of awareness of each other and of a sense of natural intimacy (Dalsgaard, Skov, \& Thomassen, 2006; Zuckerman \& Maes, 2005).

Due to the development of communication technologies in this information age, a variety of digital devices, instant messaging and social networking services have emerged that support family communication and interaction on a daily basis. People use phones, texts and emails to communicate more frequently and with ease, compared to writing oldfashioned letters. Nowadays digital information transfer is the dominant form of communication (e.g. digital text, audio and video etc.): according to a survey conducted by Habib and Khan in $2007,98 \%$ of respondents declared talking on the phone to be the most commonly used or preferred way to communicate with loved ones, while $70 \%$ preferred to communicate through e-mails (121 respondents). Although this survey was conducted within a specific target group (singles and couples), the results to generally hold true for a more general population. 
However, this verbal or even visual communication is not a substitute for physical togetherness (Grivas, 2006). Using these novel communication media, some of the emotional content and meaning of the message is often lost, compared to face-to-face interchanges or physical mail. "Emotion is communicated to others using a variety of different cues, such as facial expression, vocal intonation and body language. By integrating these cues, emotion may be communicated" (Planalp and Knie, 2002). In addition, "Communication that occurs without these cues risks a loss of meaning" (Willis \& Jones, 2012).

Although emotional factors are significant to personal communication experiences, current technologies might not be fully developed to support affective communication across a distance (Willis, 2012; Smith \& MacLean, 2007; Werner \& Hornecker, 2008). A study comparing the interaction within a large social group to that in a smaller group found that smaller groups were more effective in supporting the sharing of emotional states (Willis, 2012). Therefore, while we benefit from current communication technologies, there is a need to explore alternative means for augmenting emotional communication over distances in small groups of people.

Researchers have investigated how technology can enhance the quality of family communication based on improving existing communication tools, such as sharing photos via picture blog (Dalsgaard, Skov and Thomassen, 2006), and augmenting videoconferencing with a camera-projector system (Yarosh et al., 2009). According to Mark Weiser (1999), also known as the Father of ubiquitous computing, "The most profound technologies are those that disappear. They weave themselves into the fabric of everyday life until they are indistinguishable from it". This description predicts that the 
understanding of computing technologies will no longer stay on screen, but shift into a larger context in people's lives (Kuang, 2013). This perspective implies that there is an opportunity to integrate digital interaction with daily objects that might provide multiple ways to communicate remotely. Associated with the problem of remote communication among family members, there is an opportunity to study various forms of remote communication that can leverage other communicative sensory enhancements to better support intimacy.

In this context, sharing the light of emerging technologies in ubiquitous computing, this thesis aims to explore new forms of affective communication between young adult children and older parents living apart. The present interdisciplinary research draws from the fields of human computer interaction, sensory experience design, affective communication, and cultural studies to investigate the research topic. By understanding the patterns of remote emotional communication in the targeted groups, the current investigation aims to generate new concepts and tools for remote interaction, and identify possible future design applications.

\subsection{Purpose of the Study}

The present study concentrates on family communication, particularly between older parents and young adult children, and looks at the remote communication patterns between people from different generations who are geographically separated. The objective of this research is to discover and develop possible communication applications, and to make design recommendations for enhancing the affective experience of remote intimacy. To understand the cues that are missing from current communication models, 
the study investigates the sensory interactions in existing communication methods and other day-to-day intimate activities, which might enhance, support or build family connections. Through identifying important messages, potential sensory modalities, metaphors and meaningful artifacts, this study generates concepts for new forms of interaction tools and new user scenarios.

\subsection{Research Questions and Hypotheses}

The central question for this research is: How can users' perceptions and interaction with physical/digital objects and metaphoric imagery support remote intimate sensory experiences?

This question will be addressed by answering the following sub-questions:

1. What is the nature of intimate communication between older parents and their young adult children with respect to the activities, sensory interactions and perceptions involved?

2. How can a sensorial interface change the behavior of parents and children engaging in remote intimate experiences?

3. What metaphors associated with intimate relationships could be effective by remote communication on a sensorial interface?

Since a remote intimate sensory experience is based on understanding individual experiences in a cultural context, the meanings of such experiences are subjective and different for each participant. This research takes a constructivist approach to investigating the central research question. A constructivist approach respects the individual views people develop in their lives (Creswell, 2009), leading researchers to 
investigate the complexity of these views (Creswell, 2009) and helping them construct meaning of such experiences by analyzing triangulated findings from physical, sensory and cognitive perspectives. This approach seeks to understand the nature of remote intimacy from the aspects of user information, user activity and interaction that might relate to remote intimacy in an affective communication system.

User information involves different types of messages (i.e., affective meanings, metaphors and digital information) conveying during the communication process. This thesis hypothesizes that, by understanding how people attribute affective meanings to things in their lives, it may be possible to transfer those meanings to new technologies. These potential technologies might be able to facilitate new interaction forms that leverage other sensory ways of communicating to stay in touch and enhance remote intimacy.

\subsection{Significance}

Intimate family relationships, mutual care and the frequency of interactions influence the well-being of family members. As young adult children become more independent, and move away from the family cluster for education, work or to create a family, physical separation decreases the time they have for interacting with their relatives left behind. Therefore, maintaining and improving communication and connections in such distributed families is imperative.

The participants in this study are young adult children who live at a distance away from home and family members. They are interested in improving the quality of their emotional communication with their parents, while living separately. By investigating 
current communication activities for supporting intimacy, this research explores possible alternative solutions to enrich such emotional experiences.

Designers, researchers, and other professionals doing related work to improve the quality of emotional communication in distributed family contexts might benefit from this research through a greater understanding of the nature of remote interaction and emotional experiences. The results outlined by the present research will (1) offer recommendations for developing new kinds of design elements for remote interactions; (2) demonstrate the potential for certain features that are valuable for designing the interface of interaction artefacts; (3) and help understand the role and possible applications of communication technology in future studies.

Wearable technologies have recently emerged but are still in the early stages of development and have yet to become more functional to better fit into people's lives. Beyond the investigation of functionality and feasibility, cultural needs are also a significant aspect in clarifying the meanings of wearable technologies. By exploring new concepts for communication tools that support remote affective communication, it may be possible to explore the application of wearable technology in the future, which could enrich the cultural meaning of technology in an inter-personal communication context.

\subsection{Structure of Thesis}

The first chapter introduces the scope of this study and the related issues that describe the context of communication technologies. It also defines the research questions and hypothesis for investigation. Finally, the rationale and the significance of this research are presented. 
The second chapter is a literature review. It discusses the theoretical framework of remote emotional communication supported by the context of technologies. Starting with an overview of currently available technologies for family interaction over long distances, it explores the meaning of emotion and intimacy from both human and technology perspectives. Furthermore, the cues and methods in supporting remote affective communication provide the possibility to challenge existing means of interaction and explore the potential for new communication artifacts in the future. The last section describes the framework for the methodology of conducting this study.

Based on the theoretical framework from the existing literature, the third chapter describes the systematic methods for conducting this research. It introduces the objective of each phase, method design, ethics, and the data collection procedures. Mixed methods were used throughout the whole process. The methods consist of Diary studies, the analysis of initial data, and generating materials for a subsequent Co-design workshop. This approach takes an exploratory strategy to promote the understanding of the emerging themes step-by step, and extracting the possibility of new communication tools rooted in the families' daily lives.

The fourth chapter presents the findings. The results are divided into two parts, the Diary study and workshop, and each part is organized by categories. These categories are generated from the analysis of the themes of family communication, artefacts, the cues involved in supporting interaction (sensory modalities and metaphors), and other design criteria. 
The fifth chapter analyses the findings in view of their relevance to the research questions and evaluates the initial hypothesis that prompted the study. By integrating the findings extracted from the investigation process with the theoretical framework from the literature reviewed in chapter two, the researcher aims to offer recommendations for the design of new communication tools for enhancing family relations.

Finally, in the concluding chapter, the key points learned during the investigation process are summarized, presenting insights for improving remote family interactions and the contributions of the present study. The researcher also clarifies the limitations of the research and points towards possible directions for further exploration in the future. 


\section{CHAPTER 2: LITERATURE REVIEW}

This chapter provides a review of the relevant literature, which explores the fields of social communication/communication media, human computer interaction and technology and methodology. The first section introduces the general background regarding the use of current communication technologies. It raises the issue of supporting emotional communication, as a premise for discussing affective communication, remote intimacy and presence in the second section. The third explores the relevant cues involving sensory enhancement, metaphors and related methods of affective measurement that relate to emotional intimate experiences. The following section investigates the meaning of intimacy in the context of technology, which inspires the idea of searching new means of interaction. The next part reviews the literature in order to provide information about methodologies, which will later be applied in this study. Finally, the following summary describes the theoretical relationship between all the relevant points to frame the rationale and questions for inquiry.

\subsection{Background}

\subsubsection{Current Communication Technologies}

With the development of communication technology, the evolution of communication methods has experienced dramatic changes in the last few decades, from initial text as the dominant form to audio, video and even three-dimensional Shared Virtual Environments (SVE) (Sallnäs, 1999). A number of devices to keep in touch with 
other people have emerged, such as: email, telefax, mobile phones, pagers, video conferencing, etc. (Tollmar, Junestrand, \& Torgny, 2000). These forms have become the most prevalent communication methods in modern daily life.

These interaction methods are complementary to one another, and reflect the diversity of current communication systems. In the Tollar and Persson's (2002) ethnographic study about family communication, they found that email was not perceived to be a replacement for voice conversations, yet was still considered essential for most people on a regular basis. This finding, along with the awareness of such diversity in communication technologies, suggests that the overall communication system could be prone to increasing its compatibility and openness to new or alternative means of communication in the future.

Although current technologies comprehensively support remote communication, many researchers stated that these technologies do not adequately support emotional communication (Willis, 2012; (Smith \& MacLean, 2007; Vetere et al., 2005). Even though current text-based messages (SMS), sound and image communication have applied punctuation, spelling and emoticons to take the place of body language, facial expression and vocal intonation used during face-to-face interactions as cues of emotional expression (Riordan and Kreuz, 2010), they still lack the ability to convey emotion in an accurate manner, often times leading to confusion or misinterpretation (Willis \& Jones, 2012).

On the other hand, Willis and Jones' research (2012) found that small groups were most effective for supporting the sharing of emotional states as compared to large 
groups. They stated, "the trend towards encouraging large group membership in our social networking services is creating an environment in which the communication of emotion may be discouraged" (p.657). This reveals the need for supporting emotional exchanges in personal or inter-family members communications.

\subsubsection{Related Studies Targeting Parent-Children Communication}

Intergenerational social connections between children and their parents are vital for the well-being of immediate family members (Dalsgaard et al., 2007). However, currently available methods of remote communication (e.g. textual, visual and audio communication tools, etc.) rarely provide opportunities for the amount and type of contact parents and children need to maintain a healthy balance of a relationship (Yarosh, Cuzzort, Müller, \& Abowd, 2009). These methods also rarely allow people to fully express their intended thoughts or feelings. For instance, the telephone, while considered the most commonly used technology for family communication (Kennedy et al., 2008), might not be the best way to build closeness as compared to the natural in person physical interactions, both verbal and non-verbal (Dalsgaard, Skov, Stougaard, \& Thomassen, 2006).

Researchers have targeted teenagers and parents for prototyping tools to support remote collaborative activities or daily tasks. Share Table (Yarosh, et al., 2009) is an example that uses audio- and video-based media spaces for the intended purpose. By augmenting videoconferencing with a camera-projector system, it allows for shared viewing of physical artifacts while engaging in diverse play activities, like board games and puzzles. Huggy Pajama (Keng et al., 2009) examined hug communication as an alternative expression of verbal language. The wearable system enabled parents and 
children to "hug" one another with air pressure through a novel hugging interface device. These studies demonstrated the importance of non-verbal communication.

Additionally, photo sharing is becoming another common communication medium to maintain a presence in the lives of young adult children and their parents. eKiss (Dalsgaard et al., 2007) integrated mobile and weblog-based media to capture and send images to the family members, which provided mediating intimacy between children and parents. Peek-a-Drawer (Siio, Rowan, \& Mynatt, 2002) used furniture to support sharing images of physical items that connected family members who were located at a distance. When a user put an object into the upper drawer of the chest, an image of that object appeared on the screen of the lower drawer of the paired chest. LumiTouch (Chang, Resner, Koerner, Wang, \& Ishii, 2011) is a pair of interactive picture frames which allows remote couples to share presence and personal emotional information. When one user touches or approaches the picture frame, the other picture frame lights up to support subtle communication that could signify awareness of each other. Finally, Tangible Digital Album (Wong-villacres \& Bardzell, 2011) is a tangible device that family members could use at home to easily upload and arrange photos, and add audio messages or graphic decorations. These projects all explored different forms of technologies for sharing photos. Comparing Peek-a-Drawer, Tangible Digital Album and LumiTouch with eKiss, the last three projects identified that physical artifacts could be used to mediate intimate relationships. 


\subsection{Emotion, Intimacy and Presence}

\subsubsection{Emotion}

The existing literature demonstrates the interest in emotional communication, and the involved social-emotional theory in the context of computer use (Tollmar et al., 2000). With a specific emphasis on the importance of emotion, Planalp (1999) used the metaphors of fabric and color to describe the relationship between daily life and emotion, which implies that emotion gives life to communication in everyday interaction. Frijda and Mesquita (1991) also state that "emotion is not only an integral part of conversation; sometimes producing a certain emotion is the main or only reason for having the conversation at all". These views indicate that emotional communication is a common and effective means of establishing, maintaining, and negotiating social connections (Planalp, 1999), and that it plays a key role in behavior, cognition and communication (Broekens \& Brinkman, 2013).

Affect is hard to define due to its complex nature. Generally, it refers to a particular form of subjective experience that involves emotions. In a remote communication context, it is a type of communication that serves other purposes than purely practical ones (Tollmar et al., 2000), but refers to the processes of how people express their feelings and exchange emotional messages with one another. The present research focuses on affective communication between family members, where "affective" refers to being concerned with or arousing the emotion or feelings associated with the other person (“Affective” as per, Collins Gage, Dictionary, 2006, p23).

Broekens (2010) attributes affect to feeling, emotion, mood, attitude/preference or personal traits towards people and things. However, these synonyms are differentiated 
from one another. Broekens and Brinkman (2013) explain the meaning of emotion as "an adaptive response of an organism in order to cope with a change in the environment, associated with particular facial expression, feeling, cognitive process, physiological change and action readiness". They explain that mood presents a more silent presence of moderate levels of affect than emotion, which is more like a short and intensive episode due to a causal reason (Broekens \& Brinkman, 2013).

Apart from the view of sociologists, researchers also explore emotion in technology. The field of affective computing and human computer interaction evaluates the key role of emotion in how people interact with technology as well as how they interact with each other through technology (Broekens \& Brinkman, 2013; Bickmore \& Picard, 2005). This close relationship introduces an important concept (or process of identifying) called the Affective Loop (Paiva, 2000). It consists of a five-step process involving different affective abilities of the technology involved: user affect detection; user affect interpretation; system affective state synthesis; synthetic affective state expression; and influence user affect (Picard, 1997). User affect detection implies enabling recognition of a user's affective states; the following three steps describe the process of how computer processing interprets and represents the user's affective states that requires the expression of emotions in the machine; and the final step shows that an interaction influences the user's affective states (Paiva, 2000). These steps describe how emotional messages are captured, coded, transferred and received in a person-to-person or person-to-computer communication process.

Planalp (1999) discussed the properties of emotion as both personal and social. This duality is based on a dialectic view suggesting that our feelings are neither entirely 
personal nor social. On the personal side, the author explains emotion as individual and private. He says, "Emotional communication is commonly expressed physically and thus is closely linked to the body, the ultimate locus of the personal self" (p135). On the social side, emotion is considered to be associated with the interactional perspective that encourages the exchange of emotional information and the sharing of personal experiences. He says, "Most of our feelings are directly connected to situations involving other people, and so we communicate emotion about and with other people...without shared meaning and no implication for others, there would be no need to communicate emotion" (p135). To some extent, emotions promote and regulate social and communicative connections (Metts \& Bowers, 1994).

\subsubsection{Intimacy \& Tele-Presence}

If emotional communication were both personal and sociable as Planalp (1999) describes, it would raise the question: with whom do people usually share emotion? This question points to another intimate layer of emotion, which serves a significant role in the case of close relationships like families and couples. Planalp (1999) suggests that "as adults, our emotional messages are adapted most to the people with whom we coordinate the most strongly and the most often - our intimate partners; even when emotions are negative, they are difficult not to share". The emotions that people feel in such close relationships are strongly connected and influence each other (Planalp, 1999).

Accordingly, the concept of intimacy is important. Intimacy can be defined as "our innermost selves, something personal, closely felt, [and] such a construction could include love, closeness, or spirituality" (Bell and Brooke, 1991). Moreover, intimacy is usually connected with physical togetherness (Grivas, 2006a). For instance, it could refer 
to experiencing a feeling of closeness and togetherness between two family members; however, this sort of feeling might not occur in regular long-distance communication.

The level of shared intimacy could be affected by a number of factors, such as physical distance, eye contact, smiling and topics of conversation (Sallnäs, 1999). In this regard, the concept of Tele-presence was introduced. It relates to the Social Presence theory (Short et al., 1976) to scale the interaction and the experience of remote intimacy (Tollmar, 2002; Samani et al., 2012). Presence could also be defined as "the subjective experience of being in one place or environment, even when one is physically situated in another" (Witmer, 1998). In the context of a virtual environment, presence refers to experiencing the computer-generated environment rather than the actual physical locale (Sallnäs, 1999).

For the purposes of this research presence is defined as accepting the premise of physical distance and space, without being necessarily linked to verbal expression. Grivas (2006) claims that "verbal or even visual communication cannot substitute for physical togetherness in the context of presence, for they generally lack spatiality, sensitivity, and demand for attention" by "spatiality" implying -as believed- that shared space that is lacking in remote communication, which is also devoid of sensitivity. He gives an example in support of his idea that "spatiality" as shared space is required in the concept of "presence": the simple situation of two persons being present in the same house can create the sense of togetherness, even without any other form of interaction between them. This example emphasizes that current communication activities (i.e. phone, video) do not necessarily provide that sense of presence or togetherness. 
To mitigate the two opposite implications above, Grivas (2006) believes that the need to share personal space and daily life with remote people and places is not a fictional scenario. In his project Digital Selves, he attempts to promote the creation of a mediated environment for people to share the sense of the other's activity and presence. It allows two subjects to manifest in each other's physical house, as if they inhabited a common intimate space.

Finally, (Sallnäs, 1999) suggested that communication media are perceived as warmer and more intimate when they can transmit and capture non-verbal cues like facial expressions and posture. This view pointed out that other factors affected the level of presence, such as sensory enhancement and metaphors. Different media affect the process of communication differently and determine the accuracy of information transmission, due to the difference in their capacity to carry different data that is rich in information (Rice, 1993). Researchers also stated that in communicating emotion, people need a variety of different cues to support it, and without these cues, there would be a risk of losing meaning (Willis, 2012; Planalp, 2002). Therefore, the various aspects and the differences in the types of media that support the conveying of emotion and the different sense of presence are important aspects to consider and investigate.

\subsection{Cues, Sensory Enhancement and Metaphors}

\subsubsection{Sensory Enhancement}

The sensory channels that contribute to emotional messages include voice, gestures, body movement, physiological cues, action cues, and verbal cues. Each of these could communicate through related sensory channels (Planalp, 1999). 
Most of current research examines the role of sensory modalities in intimate communication. Researchers believe that increasing sensory information could evoke intimate awareness and other emotional qualities. Ackerman (1990) stated that "the integrated stimulation of our five basic senses: touch, taste, hearing, sight and smell causes our cognition to be more fully engaged". To enrich the capabilities of the communication tools in order to convey such emotional experiences, this literature review looks at potential design methods and concepts in the areas of sensory and interaction design.

In a general sense, touch is a powerful channel for emotional connectedness in intimate relationships (Smith \& MacLean, 2007), and human beings are used to interacting via tactile stimuli while being part of a partnership (Werner and Wettach, 2008). However, this channel is generally not available in remote contexts (Smith, 2007). This suggests there is an opportunity to study ways to enhance the effect of tactile modalities in remote affective communication.

Many researchers have examined the tactile modality for stimulating remote emotional communication through responsive devices. United-pulse (Werner, 2008) is a pair of two rings that use vibrations based on a wearer's pulse to create remote intimate communication. Kissenger (Samani, 2012) is an interactive device, which provides a physical interface for transmitting a "kiss" between two remotely connected people. These two projects incorporated a tactile modality as the interactive stimulus to support remote intimacy, and they each proposed some sort of symbolic link (i.e. photo, pulse, ring, and kiss) to embody the physical interface for intimate communication. In addition, they utilized the forms of artifacts rather than the conventional form of digital devices. 
These forms provided a different context for applying tactile stimuli. Compared to the active touch of Kissenger, the passive touch of United-pulse provided a wearable form that might have different means of interaction in a user scenario.

Besides the tactile modality, visual and other sensorial modalities also support communicating affect and emotion. Schifferstein (2011) suggested a multi-sensory design approach, which breaks down the methodology into several phases. Referring to the context of this research, the steps include: selecting emotional information or expressions that a person wants to convey in remote interaction, exploring the associations and sensory properties related to the selected expressions, understanding the relationship between expressions and sensory properties, organizing a mind map of the information, and developing user-interaction scenarios. This approach describes a step-by-step concept development process involving multisensory modalities in designing emotional interaction.

Another study discusses Sensorial Interfaces, which can articulate information expressions across different modalities through augmenting existing physical objects and sensory mappings (Chang and Ishii, 2006). Digitally augmented objects integrate digital information and interactive properties into conventional objects. They use sensory mapping as a method to associate the activity (operations and actions) with the digital medium (inputs and outputs), which can develop an interaction flow for using sensorial interfaces.

The design process of sensorial interfaces relies on understanding the senses (sensory inputs and outputs), the physical semantics of an object (the meanings and 
expressions aimed to convey via an object), and the rituals of the object's usage (the actions and operations people follow when interacting with an object) (Chang, 2006). By bringing these different aspects into a whole interaction process, designers are able to build a connection between the interactive objects or interfaces, user activities, and the digital/ sensory information communicated. Also, the design process guides designers and researchers to break through the two-dimensional graphic user interface paradigm of current digital interfaces and explore multi-sensorial interfaces in their projects.

MusicBottles (Ishii, Mazalek, \& Lee, 2001) illustrates this principle. This installation used a collection of transparent bottle-formed interfaces that interact with digital information across tactile, visual and auditory modalities. The simple action of opening the vessels would release the music "stored inside" the bottles. This example demonstrates how digital information can be carried via diverse channels and tangible forms of familiar artifacts.

\subsubsection{Metaphors and Semantics}

Apart from sensory aspects, relationships were also an important factor for developing artifacts that functioned as a representation of remote presence (Tollmar, 2002). Tollmar et al. examined the role of artifacts in supporting emotional closeness. They found that the objects utilized for communicating intimacy should have some sort of affection, association and memory for their owner rather than just utilitarian purposes. These associations explained why metaphors enable people to attribute meanings and emotions to artifacts, and to interact with them accordingly (Krippendroff, 2006). Vetere et al. (2005) claim that intimacy can be mediated through symbols of affection such as flowers and love letters. 
Meaningful metaphors and semantics can be explored not only in physical artifacts, but also other flexible forms like adjective words, figures and certain properties. For instance, light may convey the meaning of safety and symbolic information of presence in family communication. The use of light could indicate that someone is at home and manifest the presence of life, which was described in the Light sculptures 6 th sense (Tollmar et al., 2002). Sonic Souvenirs (Dib, 2010) and Memory box (Frohlich and Murphy, 2000), sounds were explored to trigger memory and serve as a medium for family reminiscing and recorded narratives.

In essence, metaphors could serve as a design principle for exploring meaningful artifacts for communicating intimacy. The symbolic language could interpret potential design elements associated with people's emotions, and accordingly shape them into tangible user interfaces.

\subsubsection{Affective Measurement}

In the fields of psychology and affective computing, the literature discusses developing the approaches for measuring human affect. Generally, affect is explored from two different angles: implicit affect measurement (automatic affect detection) and explicit affective feedback (affective self-report) (Broekens \& Brinkman, 2013). Implicit affect measurement uses more passive and intuitive means such as: user behavior and physiological signals. "Such implicit mechanisms existed that deduce affect and emotion from different physiological modalities such as heart rate, skin conductance, facial expression and voice" (Picard \& Healey, 1997; Picard \& Klein, 2002). By contrast, explicit affective feedback asks the user to provide affective information using tools like 
self-report questionnaires (Watson et al., 1988), and the Self-Assessment-Manikin (SAM) (Bradley \& Lang, 1994; Suk \& Design, 2009).

These methods establish particular criteria or categories for affective measurement, such as the six basic categories of emotion by Ekman (1993): fear, anger, happiness, surprise, disgust, and sadness. These scales helped efficiently measure and classify expressed emotion; however, due to the complexity of affect, "people typically express a much wider variety of affective states and in more subtle ways than prototypical emotional states" (Broekens, 2013).

\subsection{Intimate Computing and Wearable Technology}

\subsubsection{Intimate Computing}

From the point of view of technology, the current literature reveals another layer of meaning of intimacy. Bell et al. (2003) predicted that for the next era, technologies and relevant appliances would respond better to our needs, delivering "smarter" and more contextually appropriate services. To achieve this goal, "computing appliances would have to become more intimate, more knowing of who we are and what we desire; more woven into our daily lives" (Bell et al., 2003). In this context, the notion of intimate computing explores the ways in which computing technology can become more personal.

Intimate computing refers to "technologies that enhance or make possible forms of intimacy between remote people, that would normally only be possible if they were proximate" (Bell et al., 2003). There are different levels identified that explain the nature (and levels) of intimacy: 
1. Intimacy as cognitive and emotional closeness with technology, where the technology (typically unidirectionally) may be aware of, responsive to and express, our intentions, actions and feelings towards others. Here our technologies know us intimately; we may or may not know them intimately;

2. Intimacy as physical closeness with technology, both on the body and/or within the body.

Many scholars support the view of contextually appropriate services that Bell et al. (2003) had mentioned. While the synergy between human senses and technology occur, intimate computing would be able to provide computers with access to the real context of daily life (Lamming and Flynn, 1994). Weiser (1999) said, "we are trying to conceive a new way of thinking about computers in the world, one that takes into account the natural human environment and allows computers themselves to vanish into the background". These views reveal the trend that the innovation in digital interaction devices will actually intrude into real life.

\subsubsection{Ubiquitous Computing and Wearable Technology}

Ubiquitous computing is the essential form of technology associated with intimacy (Bell et al., 2003). Generally, the innovative forces pushing technology to aim at better fitting into people's everyday lives (Kuang, 2013) resulted in the emergence of ubiquitous computing and the analogous term wearable computing. Weiser (1999) came up with the concept of ubiquitous computing, and defined it as the computing that "does not live on a personal device of any sort, but is everywhere in our living objects". In 1966, Thorpe and Shannon revealed the first Wearable computer (Mann, 1998); and correspondingly, Greenfield (2010) came up with the term everyware, claiming that the majority of such embedded systems will eventually link up with broader networks. These claims established the vision of technology approaching people through a variety of daily objects and a networked system. Also, it raised the concern to not only understand 
individual objects, but the networked abilities of each device. Buxton suggests that those new devices in the future should be part of systems that could coordinate with one another and adapt to users' changing needs (reference to Bill Buxton on Kuang, 2013).

\subsubsection{Embedded Techniques and Interfaces}

The ideas of ubiquitous computing and everyware brought forth the challenge to shape new technology. To truly integrate digital interaction into people's lives, designers are aware of shifting attention from computer screens to the larger world around us, from understanding the action of "push a button" to considering every nuance of everyday activity and human behavior (Kuang, 2013). From this context, embedded techniques appear to modify the form of user interface for digital interaction. In Seymour's (2008) book Fashionable Technology, the author highlights several important components for embedded techniques in wearable design: interfaces, microprocessors, inputs, outputs, software, energy, and materials. In particular, she explains that a user interface is the most rudimentary medium between computing devices and the users. The users would input their commands and receive feedback from the system. The following studies explore some new and relevant forms of user interface techniques that are different from traditional emissive or screen-based interfaces for processing information.

\section{(1) Organic User Interface:}

(Holman \& Vertegaal, 2008) observed that digital interaction is lost in the things that could be done with other real-world tools. For example, people interact differently with a digital document,compared to reading a paperback book. They note a disconnection between our interaction with current technologies and human behavior in 
real lives. To deal with such disconnection, researchers propose organic user interface, which can be simply defined as a non-flat display (Vertegaal and Poupyrev, 2008). Organic user interfaces take the approach of designing computers in any way, shape, or form as the primary means of input and output (Vertegaal, 2008), and tend to truly integrate the ways of processing information into everyday contexts. For instance, inspired from the original method of reading paper documents, the projects PaperPhone (Lahey et al., 2011) and DisplayStacks (Girouard, Tarun, \& Vertegaal, 2012) examine flexible displays that allow for the physical manipulation of digital information. By dynamically tracking the position and orientation of these displays in relation to one another, they enable a function as if shuffling a stack of paper.

\section{(2) Wearable Interface}

The wearable computational artifacts that have been shown effective for supporting intimate interactions are clothing, jewellery and other accessories. Jewellery can provide a meaningful interface to meet our social, emotional, and aesthetic needs (Miner, 2001). Compared to other devices and objects, jewellery has more intimate and portable properties, being nestled closely to people's bodies. It can also be easily accessed and can respond through intimate interaction. Willis (2012) suggests that, "mobile devices were best suited to support the sharing of personal information such as emotional states".

From a cultural perspective, although the physical forms and styles of jewellery have greatly evolved from ancient times to the present, it has generally kept its nature of being a means of personal expression (Adamson, 2007) and being tied with interpersonal meaningfulness. For example, lockets communicate a sense of intimacy, as tools to 
record memories for self-reflection, identity and reminiscence (Wallace and Thieme, 2012); and wedding rings represent particular cultural meanings in a close relationship (Hopper and Knapp, 1981). These forms indicate the potential use of jewellery as a meaningful, intimate and affective medium for inter-personal communication. However, traditional jewellery and other wearables usually have fixed and static expressions. By integrating the traditional forms of these artifacts with wearable technologies, multiple and dynamic expressions might be found for new communication purposes.

\subsection{Methodology}

By taking a hybrid exploratory research approach using mixed methods, this section will review the methods of using cultural probes and co-design workshops to identify suitable methods for this investigation.

\subsubsection{Mixed Methods}

Mixed methods research refers to the type of research that combines elements of qualitative and quantitative approaches for the broad purposes of breadth and depth of understanding and corroboration (Johnson, Onwuegbuzie and Turner, 2007; Creswell, 2011). It attempts to consider multiple viewpoints, perspectives, positions, and standpoints rather than that of qualitative or quantitative studies (Johnson, 2007). This method allows researchers to broaden their understanding of the research topic, and integrate a variety of perspectives. This method is suitable for this research, as it needs to bring multiple perspectives from intimate, sensory and technological aspects to construct the meaning of the experience in the situation being studied. 
Furthermore, scholars have identified rationales for using mixed methods. First, this type of methodological study integrates the strength of each type of approach. At the research design stage, "quantitative data can assist the qualitative component by identifying representative sample members" (in this case, identifying the most important themes emerged from data); and in contrast, "qualitative data can assist the quantitative component of a study by helping with conceptual and instrument development"' (Sieber, 1973). Second, by applying multiple methods, using the results from one method could help inform the other method and reframe further research questions (Greene, Caracelli, and Graham, 1989).

On the other hand, the reliability and validity of qualitative results are questioned more frequently than that of quantitative results due to their different connotations (Creswell, 2009). In order to check the accuracy of qualitative results, triangulation is a way to refine validation for qualitative data. It consists of strengthening qualitative findings by comparing results from several independent sources (Decrop, 1999). In doing so, the results from multiple data sources and perspectives allow researchers to be more confidential about results and interpretation.

\subsubsection{Exploratory Research}

Babbie (2007) identifies three types of purposes for social science research: exploratory, descriptive, and explanatory. Exploratory research is used when problems are in a preliminary stage (Babbie, 2007). It is a broad-ranging, purposive, systematic, prearranged study designed to maximize the discovery of generalizations leading to description and understanding an area of social or psychological life (Stebbins, 2001). As 
this study is exploring a new means for remote communication, we selected to conduct an exploratory investigation.

The current literature has not yet clearly defined the pattern of affective communication in the context of family, and still lacks information about the factors that influence affective communication through technology. Therefore, this study hopes to gain a better understanding of the general knowledge regarding the research questions and to gain insights that may contribute to developing new means of communication. This study thus could benefit from the attributes of exploratory research, which gathers preliminary information to help define problems and suggest further research directions.

\subsubsection{Scenarios}

Accordingly, in order to investigate new possibilities for the research topic, this exploratory study needs to investigate the potential future scenarios from users. Different from the story used to illustrate how an existing artifact or system can be integrated into people's lives (Kolko, 2010), potential future scenarios are narratives more likely to explore the future use of a product from a user's point of view, helping design teams think about its place in a person's day-to-day life (Hanington, 2012). By telling a story, this method enables to build a personal experience as the participant engages with a product or a service (Hanington, 2012; Kolko, 2010).

Even though fictitious scenarios are not always true, Hanington \& Martin (2012) explains that they still help researchers understand users' activities, feelings, and desires. There are some advantages of utilizing future scenarios. Hanington \& Martin (2012) summarize some of these advantages as follows: 1) making design ideas more explicit 
and concrete, so that the design team can empathetically envision the future ways in which a product is likely to be used; and 2) helping avoid the tendency to design toward technical requirements, instead focusing the efforts on building culturally meaningful artifacts that augment actual day-to-day human activity. They amplify the second point stating that "scenarios should be written from a person's point of view, and focus more on what technology enables, rather than the details of the technology itself" (Hanington \& Martin, 2012).

Scenarios are flexible, and take on many variations in form, such as written and visual forms (Hanington, 2012). Visual forms are especially suitable for creating scenarios, because it is believed that a graphical language focuses thought even more intensively than a textual language with thousands of words (Beyer and Holtzblatt, 1998). It lets you take in a whole picture at once, and is easier for researchers and other participants to see what the user is talking about.

\subsubsection{Cultural probes and Diary studies}

To truly understand the possibility of a new means of future communication, the users should be involved in the dialogue for developing the design concept. It draws attention to cultural probes as an important methodology. Hanington \& Martin (2012) identifies Cultural probes and Diary studies as part of the methods in exploratory research, which could be used as the primary means to gather background information about the subject group and initiate grounded theory. Also, cultural probes are the instrument given to participants to inspire new forms of self-understanding and 
communication about their lives, environments, thoughts, and interactions (Hanington \& Martin, 2012).

Cultural probes are suitable for the research in the nature which intends to use returned kits to collect inspirational data for developing new design concepts and future possibilities, rather than dealing with present problems and solutions (Gaver, Dunne \& Pacenti, 1999). There are some case studies of this nature that have used this approach, such as the empirical study by (Dalsgaard et al., 2006) and the research (Vetere et al., 2005). Both of them used cultural probes to investigate how interactive technologies are used for mediating intimacy in families in imagined future scenarios.

Different from traditional methods, the characteristics of this approach are informality, flexibility and open-endedness, and could consist of any number of materials like journals, recording devices, and various pieces of text and imagery to guide personal responses (Hanington \& Martin, 2012). Rather than collecting comprehensive information and conducting a formal analysis, cultural probes intend to gather fragmentary clues about people's lives and thoughts, and serve as inspirational pieces to identify key patterns and themes that might emerge from a participant group or culture, beginning a conversation about possibilities that might exist through design (Hanington \& Martin, 2012).

A Diary is a critical component of the materials for probe kits. Mattelmaki's (2006) research Design Probes concentrates primarily on probes based on selfdocumentation. Diaries and camera studies were the most typical forms of traditional self-documentation. Mattelmaki (2006) defines Diary studies as an approach for sampling 
self-reported participant interactions or events over time. They could be the guiding artifacts that allow people to unobtrusively and expressively convey personal messages about their daily life and events without intrusive observation by researchers, and thus to help the designers understand the user groups for further research (Hanington \& Martin, 2012; Dalsgaard et al., 2006). Though Diary studies are typically conducted with a relatively small sample size, common themes and patterns can emerge (Hanington \& Martin, 2012). This is suitable for collecting qualitative data when it is not feasible to recruit a large number of participants.

Another advantage of applying Diary studies is the time factor. They are ideal for collecting information from participants across time, sampling their thoughts, feelings, or behaviors at key moments throughout a day, week, or even longer periods of time (Hanington \& Martin, 2012). In this type of research, it is difficult to access and actually observe people's personal experience, thus making the process of understanding the family members' telecommunication activities hard to assess. Participant self-recording allows the researcher to collect the information over a wide-range of time, and participants' reflection on real-time experiences can be more precisely recorded with their

fresh memories. Mattelmaki (2006) states "design probes support empathic understanding through information gathering over a prolonged period, where the researcher cannot be present".

\subsubsection{Creativity and Co-design process}

Extending from cultural probes and Diary studies, Hanington \& Martin (2012) note that journals are often used to sensitize participants to research topics, leading up to 
participatory design exercises such as collage-making, flexible modeling, or co-design workshops. Such co-design processes could utilize the background journal information to generate inspiration for a new design concept. Sanders and Stappers (2012) also claim that design models must be made with people. By co-creating with the people who are impacted by the design, we can ensure that the tools we design can actually meet their needs.

Sanders and Stappers (2008) state that "designers have been moving increasingly closer to the future users of what they design and the next new thing in the changing landscape of design research has become co-designing with users". This perspective describes the developing trend in design, which has evolved from a user-centered approach to participatory design and co-design. In user-centered design, designers and researchers place end users of a product at the center of design; they mainly involve endusers during the phases of requirements gathering and usability testing (Abras, MaloneyKrichmar and Preece, 2004). Whereas, participatory design and co-design suggest the active involvement of users in the process, to help ensure that the designed product/service meets their needs (Sanders, 2012). This illustrates how the roles of the designer, user and researcher have changed in this process, because the people formerly known as "end-users" become acknowledged as co-creators and participants in the process (Sanders, 2012).

As a subset of participatory design, Sanders and Stappers (2012) also discuss the role of the participants in a co-design process:

In a co-design process, the person who will eventually be served through the design process is given the position of "experts of their experience", and plays a large role in knowledge development, idea generation and concept 
development. In generating insights, the researcher supports the "expert of his/her experience" by providing tools for ideation and expression (p25).

It is notable that at the end of this description, the tools for ideation and expression are identified as important factors of the co-design process. In order for participants to take on the role as described in a co-design process, they must be given the appropriate tools for expressing themselves, which are usually designed by designers or facilitators prior to the workshop (Sanders, 2012). The use of physical artefacts as thinking tools throughout the process is another key characteristic of participatory design (Sanders, 2012).

In practice, the long-term "InterLiving" projects (Westerlund et al., 2003) followed a collaborative venture to develop and test a variety of design ideas. They explored a number of innovative communication artifacts to facilitate distributed family interaction. This case study suggested that co-design methods were effective in exploring innovative design concepts while there were no specific solutions or constraints in mind during the initial phase.

On the other hand, co-design facilitates collective creativity (Sanders, 2012). Sanders and Stappers (2012) use two important notions, co-creation and co-design, to describe creativity in the design process. Co-creation can refer to any act of creativity that is shared by two or more people (here known as "end-users"), and co-design as a specific instance of co-creation that involves the creative collaboration of designers and people not trained in the design development process (Sanders, 2012). Creativity is an important aspect in facilitating new ideas in the design development process, which influences the 
ability to produce novel and appropriate works within design, especially in problem solving (Sternberg and Lubart, 1995).

Sanders and Stappers (2012) identify a framework for individual creativity, which has four layers of context that contribute to creativity, including head, heart (emotion), body (activity and motion) and materials/places/spaces (environment). They believe that this framework can synergize creativity in a social or collective context.

A number of scholars discuss the perspective of collective creativity. Csikszentmihalyi (1996) states that, “creativity does not happen inside a person's head but in the interaction between a person's thoughts and a socio-cultural context". Sanders and Stappers (2012) believe that when people come together, the number of ideas and the breadth of the ideas that are brought to the table increase dramatically. Sawyer (2006) claims that all true innovations originate in collaboration rather than through the efforts of the solitary genius. These perspectives support the appropriateness of the co-design method to facilitate collective creativity.

\subsection{Summary}

Overall, this literature review identifies an opportunity for exploring new means of remote interaction between young adult children and older parents. The current chapter, raises the problems and presents an overview of various perspectives of intimacy/emotion in existing literature and evolves to question the nature and meanings of the remote intimate experience; the views expressed in literature, communication media and technology lead to inquiries on the potential cues and new forms that might enhance 
remote intimacy; finally the review of methodology helps identify appropriate methods of design for conducting this investigation.

First, the physical separation between young adult children and their parents might create not only a physical disconnection but discourage an awareness of each other, thus affecting not only family dynamic but vital family wellbeing. Although a variety of technologies have been developed to support family communication over distance, many researchers believe that these do not support emotional communication adequately, which is especially important for the social interaction in small groups. This in turn, raises the question of understanding the nature of intimate communication between older parents and their young adult children with respect to the objects, sensory interactions and perceptions involved.

Furthermore, by reviewing related studies, this research identifies two types of projects and techniques for supporting the parent-children communication. The first type is focused on improving and developing existing communication methods (e.g. camera and screen-based applications), and the other draws attention to the use of physical objects and photo sharing. Since conventional methods are still missing remote affective communication, physical forms as an alternative means for remote interaction need to be further investigated, which might involve those media or cues supporting remote affective communication.

On the other hand, from technological perspective, emotion plays an important role in how people interact with technology. The perspective from affective computing emphasizes the important affective abilities that technology should be able to offer in the 
process of conveying emotional messages. Also, the concept of intimate computing leads to the idea that bringing these technologies close to people might enable technology to sense people's feelings and emotions, and thus allow them to exchange emotional messages easily and immediately. This view encourages consideration of intimate technology as a possible solution for exploring new means of communication.

Inspired by this notion, the literature introduces the concepts of intimate computing, ubiquitous computing and wearable technology, promoting the idea of unobtrusively embedding technology into our daily lives and pervasive environment. Based on this, embedded techniques and several relevant new forms of interfaces come up, including organic user interfaces, non-emissive interfaces and wearable interfaces. These instances provide the basis to explore potential forms of interfaces rooted in people's daily lives as new means of interaction.

All these views above provide the opportunity to transition to the second question posed by this research: how can a sensorial interface change the behavior of parents and children engaging in remote intimate experiences by applying physical objects rooted in people's daily lives?

Next, the literature review explores multiple layers of meaning of intimacy from social and technological points of view. The sociological perspective identifies the meanings of emotion, intimacy, presence, and the personal and social properties of emotional communication. It also explains some existing approaches for affective measurement. The literature also discusses associated cues and media affecting emotional communication, especially emphasizing the aspects of sensory modalities and metaphors. 
Relevant sensory design approaches and projects suggest the use of sensory and symbolic cues to enhance connectedness and emotional interaction. This idea inspires the use of sensory enhancements and metaphors for investigation that leads to the second/third subquestions, exploring what sensory enhancements and metaphors associated with intimate relationship could be effective for remote communication. A sensorial design approach suggests taking artifacts, activities and information into account when building sensory enabled digital interaction. These become important factors to investigate in the study.

In this general context, the last section investigates suitable methods for designing research. The author first discusses the advantages of mixed methods that allow understanding the depth and breadth of the research topic from multiple perspectives. This method is suitable for the research, as it needs to bring multiple perspectives from intimate, sensory and technological aspects to construct the meaning of the experience in the situation being studied. Consequently, numbers are not considered to be the most important factor affecting results; instead, this research primarily emphasizes a qualitative approach and a subordinate quantitative approach. Thus, a small sample size can meet the qualitative data requirements.

In addition, the properties of exploratory research suggest that they were suitable for defining a problem in its preliminary yet wide-ranging stages. This feature dovetails with the nature of this research because it aims to investigate new design opportunities rather than existing concepts. Finally, under the landscape of participatory design, cultural probes and co-design methods are proposed to involve users in the process of designing new concepts, and help collect inspirational data to facilitate collective creativity in later stages. 


\section{CHAPTER 3. METHOD}

This chapter describes the methods applied in this research in chronological order. This exploratory research involves mixed methods: a Diary study and a collaborative workshop. The Diary study was designed to further the understanding of existing communication patterns and to collect inspirational elements from the participating family members. Then, the Diary data was used to generate materials for further investigation and to conduct workshops. The workshop was composed of three methods: card sorting, prototyping and scenarios, which explored ideas about new interactive tools for augmenting the sensory experiences of remote intimate family communication. The final step was coding and analyzing the resulting video/audio recordings and photos to gather findings and insights.

\subsection{Participants}

\subsubsection{Diary Study}

Since this research concentrated on the question of how older parents and young adult children interacted with each other over long distance in their daily lives, the study involved these two different age groups. The sampling method used a combination of purposive and convenience sampling by recruiting two groups of participants by email and through referrals from colleagues and friends. The first group was composed of 7 parents (average 52 years old, 2 men, 5 women) who communicate regularly with their children who no longer love at home. The second group contained 8 students (average 25 
years old, 3 men, 5 women), who had moved far away from home, and also communicated with their parents remotely. The interest of this study was to understand the nature of remote emotional experiences between these two roles, as well as other factors related to such experience.

\subsubsection{Workshop Activities}

Similar to the Diary study, the workshop sampling method was again a combination of purposive and convenience sampling. 4 older parents and 6 young adult children were invited to participate in 3 identical workshops separately, with 3 participants who had done the Diary study (1 parent). The ten participants were divided into five pairs to complete the workshop tasks, and balanced for gender, and for participant roles (parent/child). Table 1 illustrates the group distribution.

\begin{tabular}{cll}
\hline GROUP & ROLE & GENDER \\
\hline \multirow{2}{*}{ No.1 } & Parent & Female \\
& Parent & Female \\
\hline \multirow{2}{*}{ No.2 } & Parent & Female \\
& Child & Male \\
\multirow{2}{*}{ No.3 } & Child & Female \\
& Child & Male \\
\multirow{2}{*}{ No.4 } & Child & Female \\
& Child & Male \\
\multirow{2}{*}{ No.5 } & Parent & Female \\
& Child & Male \\
\hline
\end{tabular}

Table 1. Participants' demographics and groupings

\subsubsection{Ethics}

The study was approved by the Carleton University Research Ethics Board as posing minimal risk to the research participants since there were no physical risks, sensitive topics, or private content to be discussed. Potential participants were informed about the purpose and the nature of the study in advance, and they gave their consent to 
participate in the study. Participant information was kept confidential and anonymous: the identity of participants would not be revealed in the results or any forms of presentation, and the data were anonymously coded before storing and analyzing it.

Finally, recorded data would be destroyed after one year, though participants can request to delete certain types of private information immediately and to withdraw from the study at any time (Appendix D).

\subsection{Diary Study}

\subsubsection{Objective}

The objective of the Diary study was to understand the nature of remote communication between young adult children and older parents. Specifically, this study targeted the use of tools to enable remote communication (i.e., phone and laptop), associated artifacts, themes related to family conversation or emotional experiences. By exploring these aspects, it was then possible to generate important themes and categories as inspirational materials. These could inform further research questions and contribute to a framework for conducting workshops to explore new means for supporting emotionally intimate interactions.

\subsubsection{Materials and Procedures}

\section{(1) Daily communication activities}

Participants recorded 2 instances of their communication activities with their parents/children within a specific week. If they were unable to contact their family twice in one week, they were allowed to include an instance from another week or recall their most recent experience. The questionnaire required the following data: whom they spoke 
to, the tools, locations, duration of the communication, and the description of the communication steps of how they interacted with the devices or software (Appendix A). The Diary encouraged participants to list the significant moments during the activity (i.e. saying hello or reporting a concern), and to state their emotional feelings when communicating with the person and using the device(s). The questions used stars (1-5) as a scale to measure their positive and negative feelings as shown in Figure 1.

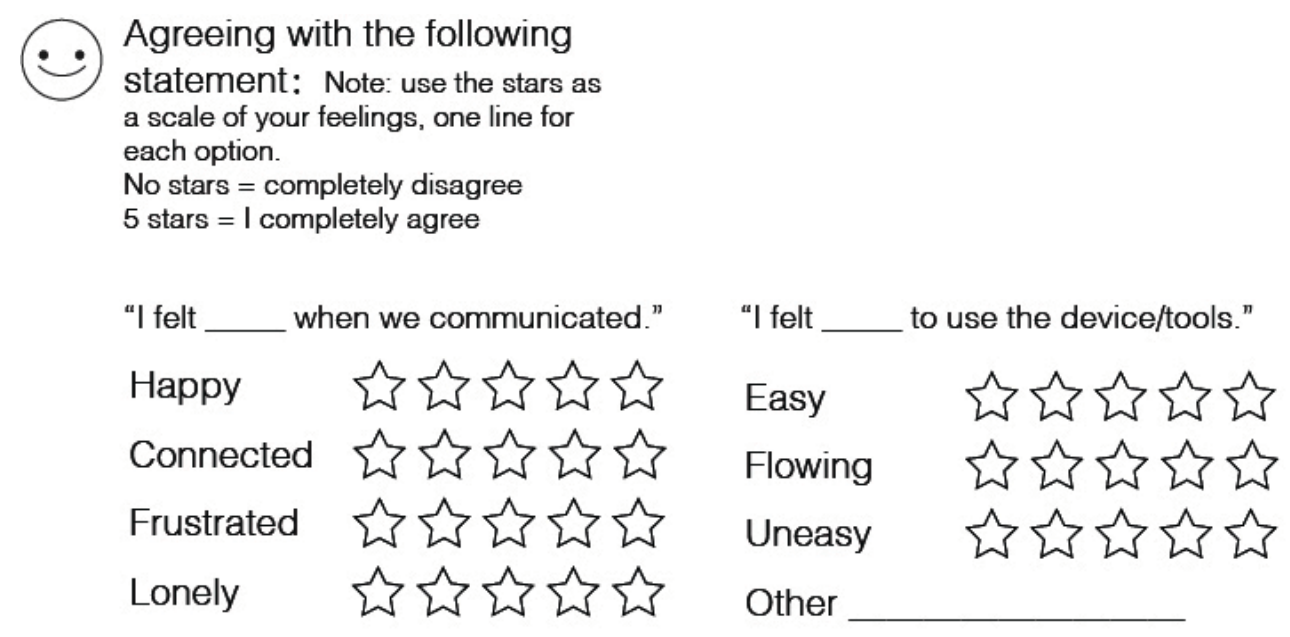

Figure 1. Questionnaire sample

\section{(2) Emotional expressions}

Emoticons are the graphic representations of facial expressions that are commonly used in current means of communication. These symbols are considered as substituting for the nonverbal cues that are missing from computer-mediated communication in comparison to face-to-face communication (Walther \& D'Addario, 2001). In the second part, participants chose 5 types of emotional expressions that they most often used in their communication with family members by giving a set of emoticons (Figure 2). The objective was to understand the meaning behind the icons rather than just knowing the expressions they used. Since people might interpret the emoticons in different ways 
depending on personal experience, they were asked to write down the meanings they assigned to each selected emoticon.

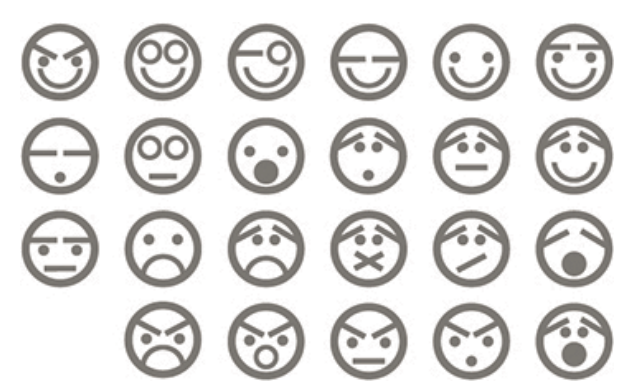

Figure 2. The list of emotional expressions

(Retrieved from http://www.vectorstock.com/royalty-free-vectors/emotion+icon-vectors)

\section{(3) Memorable objects}

Next, each participant described two of his or her most memorable objects associated with their children/parents, which reminded them of their family members. The objective was to find other factors contributing to maintaining family relationships other than the use of traditional devices (e.g., phone and laptop). Participants provided word and/or image information about the physical appearance of the objects (i.e. a gift or family photo), explaining why these special objects were memorable and associated with their family, as well as how they interacted with the objects (Appendix A).

\section{(4) Imagination exercise}

In the last section, participants used their imagination to explore 4 symbolic things that they associated with family affection or a sense of family. A questionnaire instructed participants to think about any associated things, words, graphics, and/or photos, abstract or concrete. The intention was to extract meaningful metaphors that could represent the emotional message in remote communication scenarios, as well as to understand the meaning of family affection between older parents and young adult children. 


\subsection{Workshop Activities}

\subsubsection{Objective}

The objective of the workshop was to further the findings of the previous stage, the Dairy Study, and to explore possible future scenarios that would address the opportunities identified in the previous method. This step aimed at exploring whether, by applying new technologies to some of the memorable objects in the participants' daily lives, different kinds of interactive communication tools can emerge. In addition it was important to understand the way people would imagine and respond to these nontraditional tools. The hypothesis was that sensory enhancement and metaphors could enhance remote interactions between older parents and young adult children via these new means of communication.

Each workshop consisted of two exercises. The first exercise using card sorting explored the meanings and nature of different communication messages, and aimed at finding answers to the following questions:

1. What is the nature of these messages and how would respondents categorize them?

2. Which or what types of messages are important to them?

3. Which or what types of message would they prefer to use in communication? Based on the first exercise, the second exercise composed of making prototypes and scenarios focused more on examining the possibilities for creating new interactive tools.

1. What type(s) of communication tools would the respondents develop if they could? 
2. What inputs and outputs in imagined features would they use to represent the conveyed messages?

3. Compared to traditional tools, what type(s) of messages could the respondents convey via these envisioned communication tools?

\subsubsection{Materials}

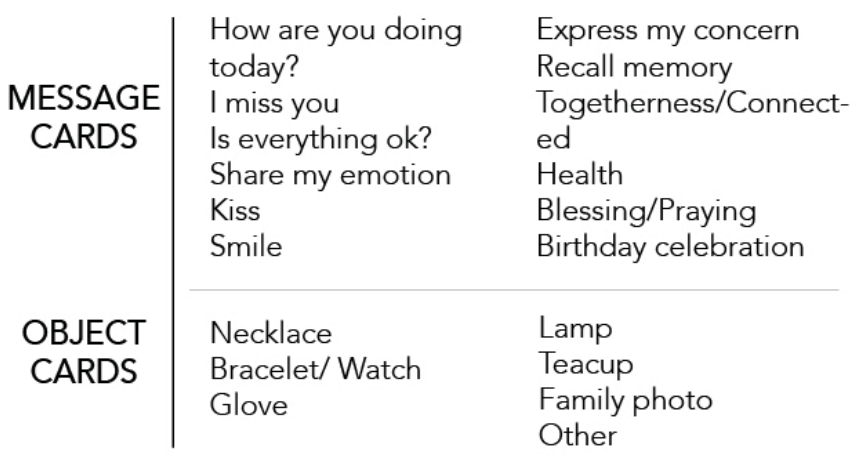

Table 2. Content of Message \& Object cards

The materials prepared for this study included: cards for sorting, prop kits, recording and video recording devices, instruction sheets and consent forms (Appendix C). Two types of cards were generated following the input data analysis obtained from the previous Diary study. The first set consisted of "message" cards, which included 13 types of messages used for exercise 1. The other one was a set of "object" cards used for exercise 2. The content of cards was exemplified in Table 2.

The prop kits were also prepared to facilitate the participants' attempt to develop ideas and models inspired by the "object" cards, such as: paperboard, teacups, gloves, mini-flashing lights, sticky notes, markers, scissors and glues etc. The prop kits were meant to help participants implement creative ideas in physical forms and share them with others. Additionally, instruction sheets were prepared to help participants 
understand the tasks more clearly. To record comprehensive data, workshop organizers setup recorders during each workshop.

\subsubsection{Procedures}

\section{(1) Exercise 1:}

The first exercise was a card sorting game. Each card contained a message idea about what participants might want to communicate, such as "I miss you" or "How was your day?". They were asked to identify what type of messages was most important to them when communicating with their children or parents. The exercise contained three steps, followed by a presentation as below:

a) Each group sorted each message into categories and gave those categories names.

b) They ranked most likely messages within each category;

c) They prioritized these categories and discussed which categories would be the most important ones to share with their family member who was far away.

d) Finally, each group shared their selection/choices with the rest of participants in the workshop.

\section{(2) Technology tutorial:}

a) After completing the first part, the organizer gave a short tutorial about the concept of wearable technology. The idea was to help participants have a basic background and understanding of the topic before starting to do the second section, so that they were able to relate to what they were asked to do.

b) In the tutorial, organizers introduced the idea that current technologies have been greatly improved enabling people to explore new ways to communicate. Heart rate 
monitors and pedometers were used to demonstrate examples of wearable technology. The idea was that participants might already be familiar with these items, which use computer chips or sensors to add smart functions or new features to wearable devices.

c) To ensure participants have the same understanding of what wearable technology is, organizers explained two important elements in designing smart and interactive objects: input and output. The simple example of a flashlight was used to demonstrate the inputs and outputs, and to help them understand how to effectively use them to create the envisioned features and functions for communication. After learning the basic concept of inputs and outputs, the workshop proceeded to exercise 2 .

\section{(3) Exercise 2:}

In the second exercise, the teams were asked to pretend that they have a magic object that can connect with their family member who is far away. Each team could choose one or more object cards that represent an object that they could imagine having in their house. It would somehow be an object they would like to be able to use to connect with their family member.

a) Participants were asked to pretend that the objects they have chosen can have input and output at both ends that somehow enables them to send messages to one another in a way that does not use words. They needed to identify 2 or 3 kinds of "magic" properties that would enable them to share the important messages or categories of messages they identified in the previous exercise. They had 10 minutes to discuss and decide what special functions the object might have: what the inputs and outputs for this way of communicating would be, in terms of what would people do with the object and how they would see and feel about it. 
b) After participants decided what they wanted the object to actually do, they used the supplies provided in the kit to make a rough physical model of the object or objects in 10 minutes, making sure that the objects included the input and output features.

c) Based on the ideas and models they developed, each team spent 10 minutes to make a user scenario. They could choose between acting it out by playing imaginary roles, or sketching pictures of the step-by-step ways that they saw their object working, or make a chart to demonstrate how it would work.

d) Finally each team had 5 minutes to act on and explain how it works.

\subsection{Data Analysis}

The data analysis refers to the methods outlined by Creswell (2009). He described the steps of the general analysis process for qualitative research and how to make sense out of text and image data and to refine the essence of the data for the study. The important steps implemented in this study include: 1) preparing and organizing data for analysis (this step included transcribing the content recorded from workshops); 2) going through all the documents, highlighting or making short notes/ summaries for the important information; 3 ) open coding text data and the pictures gathered to generate categories, themes and findings; 4) selecting the most important themes and perspectives, and comparing them within a conceptual model; 5) finally, interpreting the meaning that these themes would have in the model of these intimate communication processes, and proposing further exploration of new means of remote interaction in supporting intimacy between young adult children and older parents. 


\section{CHAPTER 4. RESULTS}

This chapter reports the results of the data gathering process. The categories and topics explored in each section follow the sequence of data collection and analysis, which aims to answer the research questions is detailed in the next chapters. The themes and expressions involved in communication activities address the first research question regarding the nature and meaning of remote emotional communication. The objects, new interactive tools/concepts and metaphors presented address the second and third question for exploring the potential sensory interfaces and metaphors for supporting remote emotional interaction between young adult children and older parents.

\subsection{Diary study}

\subsubsection{Communication Activities}

\section{(1) Communication methods}

In the section about demographic information, participants answered two five-scale questions about their familiarity and comfort with technology. The result indicates the younger generation to be significantly more familiar with technology than the older generation ( $\mathrm{t}$-test, $\mathrm{p}=0.044)$. The average score of group Children $(\mathrm{C})$ is 3.875 , which is

higher than the number 3.0 of group Parent $(\mathrm{P})$ on a 5-point scale (Table 3). For the second question, results obtained from the two groups do not show a significant difference regarding their familiarity with technology $(\mathrm{p}>0.05)$. The average scores of group $\mathrm{P}$ and group $\mathrm{C}$ are 3.43 and 4.25 respectively. 


\begin{tabular}{|c|c|c|c|c|}
\hline $\begin{array}{c}\text { AVERAGE } \\
(0-5)\end{array}$ & $\begin{array}{c}\text { How familiar } \\
\text { with technology }\end{array}$ & Stdev & $\begin{array}{c}\text { How comfortable } \\
\text { with technology }\end{array}$ & Stdev \\
\hline PARENTS(P) & 3 & 0.829 & 3.43 & 0.992 \\
\hline CHILDREN(C) & 3.875 & 1.053 & 4.25 & 0.829 \\
\hline T-TEST & 0.044 & & 0.056 & \\
\hline
\end{tabular}

Table 3. Comparison of group Parent and group Children for familiarity to technology: T-Test result and Standard Deviation

This data indicates that phones or computers are the most important and common communication tools in family communication activities: 5 parents and 8 children use instant messaging tools to communicate through cell phone or laptop. The popular programs include Skype, Viber, QQ, MSN and Oovoo. There are 4 parents and 2 children using landline phones, and one parent uses social networking (i.e., Facebook) to leave a message for her daughter and to ask for her to call back.

In the 5-scale question assessing participants' feelings while using these tools (Table 4), the highest rating adjective is "easy" that participants agreed that devices are easy to use $(\mathrm{P}=4.571, \mathrm{C}=4.625)$. Most participants agreed with the word "flowing" $(\mathrm{P}=3.857$, $\mathrm{C}=3.375$ ). The overall average score is lower than "easy", as 4 participants complain that video chat is not flowing enough. In a parent's note: "the screen and the picture are unclear and frozen at times, and sometimes we are unable to hear the conversation". Finally, most participants disagreed that they felt uneasy to use these tools in most situations $(\mathrm{P}=1, \mathrm{C}=0.875)$.

The most common place to reach family members is at home (12 participants, 7C/5P). In addition, 1 parent and 2 children mention they contact their family at school 
and office, as well as 3 parents stated they get in touch with their children when needed without a place limitation. The conversation durations vary, from 5 minutes to 2 hours.

\begin{tabular}{|c|c|c|c|c|c|c|}
\hline \multirow{2}{*}{ AVERAGE (0-5) } & \multicolumn{5}{|c|}{ I felt___to use the device/tools } \\
\hline & Easy & Stdev & Flowing & Stdev & Uneasy & Stdev \\
\hline PARENTS(P) & 4.571 & 0.354 & 3.857 & 0.969 & 1 & 0.968 \\
\hline CHILDREN(C) & 4.625 & 0.682 & 3.375 & 0.899 & 0.875 & 1.269 \\
\hline AVERAGE & 4.6 & & 3.6 & & 0.933 & \\
\hline
\end{tabular}

Table 4. Assessing participants' feeling about using devices: the average results and standard deviation

Also, the results identify the ways the participants operate the common tools (i.e. phone and laptop etc.). Talking /listening (auditory) and video (visual) are the dominant types of sensory modalities during the interaction. Touching, clicking and typing (tactile), via buttons, mouse and screen, are the basic inputs for using these conventional communication tools. In addition, the data indicates that in some cases participants would use multiple ways during one communication event, such as text messaging or calling the person first to request a video chat or express concern, and then waiting for the feedback and starting a video conversation. Participants also mentioned the detail of sending a "kiss" icon to the other person, which would make them feel more connected when they are talking via video.

\section{(2) Content of Communication}

The Diary data presents some important themes derived from their communication. The most frequent conversations start with routine greetings, asking about daily events, or reporting a concern to family members. All participants have highlighted these topics as the significant moments in their talk. 
Additionally, health and weather are important topics associated with their expressed concerns. There are 2 parents and 6 children who report their concerns about family members' health. Further, more children report concerns regarding their parents and older family members' health. Different weather conditions or events are topics of expressing concern for the family's wellbeing as well. For example, as one of the parents noted, "on a windy night, I make the call to ensure everything is all right".

On the other hand, 7 participants indicated that they would like to share emotions with each other, such as missing, blowing kisses, blessing and sharing joy. The numbers of parents and children were almost equal (4P/3C). In addition, participants $(2 \mathrm{P}, 3 \mathrm{C})$ also mention discussing daily family activities, making plans, like making a plan for a homecoming trip/visit, family events and holiday.

\subsubsection{Emotion}

Participants provided information about their emotions in two parts of the diary. First, they reported their feelings when communicating in the emotions categories of: happy, connected, frustrated and lonely (Table 5). On this 5-scale question about participants' emotional responses, participants agreed that they feel happy when communicating $(\mathrm{P}=4.813, \mathrm{C}=4.563)$. Most participants agreed that they feel connected with the other person $(\mathrm{P}=3.875, \mathrm{C}=2.813)$. The result indicates the older generation feel significantly more connected than the younger generation (t-test, $\mathrm{p}=0.036$ ). The overall average score of group Children $(\mathrm{C})$ is 2.813 , which is higher than the number 3.875 of group Parent $(\mathrm{P})$ on a 5-point scale. In contrast, when asking about the negative responses, participants state they felt less frustrated and lonely in such connections (Frustrated: $\mathrm{P}=1.214, \mathrm{C}=0.571$; Lonely: $\mathrm{P}=1.214, \mathrm{C}=0.714)$. 


\begin{tabular}{|c|c|c|c|c|c|c|c|c|}
\hline \multirow{2}{*}{ AVERAGE (0-5) } & \multicolumn{7}{|c|}{ I felt__ when we communicated } \\
\hline & Happy & Stdev & Connected & Stdev & Frustrated & Stdev & Lonely & Stdev \\
\hline PARENTS(P) & 4.813 & 0.348 & 3.875 & 1.053 & 1.214 & 0.661 & 1.214 & 0.866 \\
\hline CHILDREN(C) & 4.563 & 0.682 & 2.813 & 1.968 & 0.571 & 0.682 & 0.714 & 0.968 \\
\hline AVERAGE & 4.688 & & 3.344 & & 0.893 & & 0.964 & \\
\hline T-TEST & & & 0.036 & & & & & \\
\hline
\end{tabular}

Table 5. Assessing participants' overall feeling when they communicate

In the exercise about emotional expressions, each person chose 5 emoticons and wrote down their interpretation. The collected results in Table 18 (Appendix B) presents an overall pattern of the most likely expressions they preferred to use in communication. All expressions are placed in order on a general scale from the positive to the negative based on their explained connotation (or perceived connotation=the way they each interpreted it).

Table 6 summarizes the most frequent interpretations of these emoticons, ranging from positive to negative on a scale. The table showed that parents and children preferred to share more positive emotions with each other in conversations, and both of them felt happy and less frustrated in conversations (Positive total $=44$; Negative $=10$ ). Therefore, the overall characteristics of emotional experience in remote family communications were: happy, neutral and positive.

\begin{tabular}{|c|c|c|c|c|c|c|}
\hline & $\begin{array}{l}\text { Happy } \\
\text { Joyful } \\
\text { Smile }\end{array}$ & $\begin{array}{l}\text { Interesting } \\
\text { Naughty } \\
\text { Flirting } \\
\text { Humour }\end{array}$ & $\begin{array}{l}\text { I love you } \\
\text { I miss you } \\
\text { Blessing }\end{array}$ & $\begin{array}{l}\text { Agreeable } \\
\text { Neutral }\end{array}$ & $\begin{array}{l}\text { Questioning } \\
\text { Concerned } \\
\text { Worried } \\
\text { Speechless }\end{array}$ & $\begin{array}{l}\text { Frustrated } \\
\text { Sad } \\
\text { Upset } \\
\text { Angry }\end{array}$ \\
\hline PARENTS & 15 & 3 & 3 & 3 & 11 & 3 \\
\hline CHILDREN & 16 & 5 & 2 & 6 & 3 & 7 \\
\hline
\end{tabular}

Table 6. Interpretations of emoticons from positive to negative 
However, besides the general tendency, there were some "concerned", "inquiring" or "worried" signals in communications. Some participants expressed "concerned", "inquiring" or "worried" through emoticons, particularly in the parents group. It was noted that parents worried more often than children even though they did not express their worry directly for fear of annoying, keeping their feelings private or just expressing them implicitly. Table 7 presents participants' notes that reflected this phenomenon.

\section{Questioning/Concerned/Worried/Speechless}

PARENTS Not sure but concerned, not speak at the moment.

When I heard or read something I think is not good, I worried but have to keep quiet. Speechless; she doesn't want to be annoyed all the time.

CHILDREN About to speak but saying nothing...Zip...

Sometimes there is not much to say, and we just end our chat sooner.

Table 7. Participants' interpretation about Concerned, Worried and Speechless signals

\subsubsection{Memorable Objects}

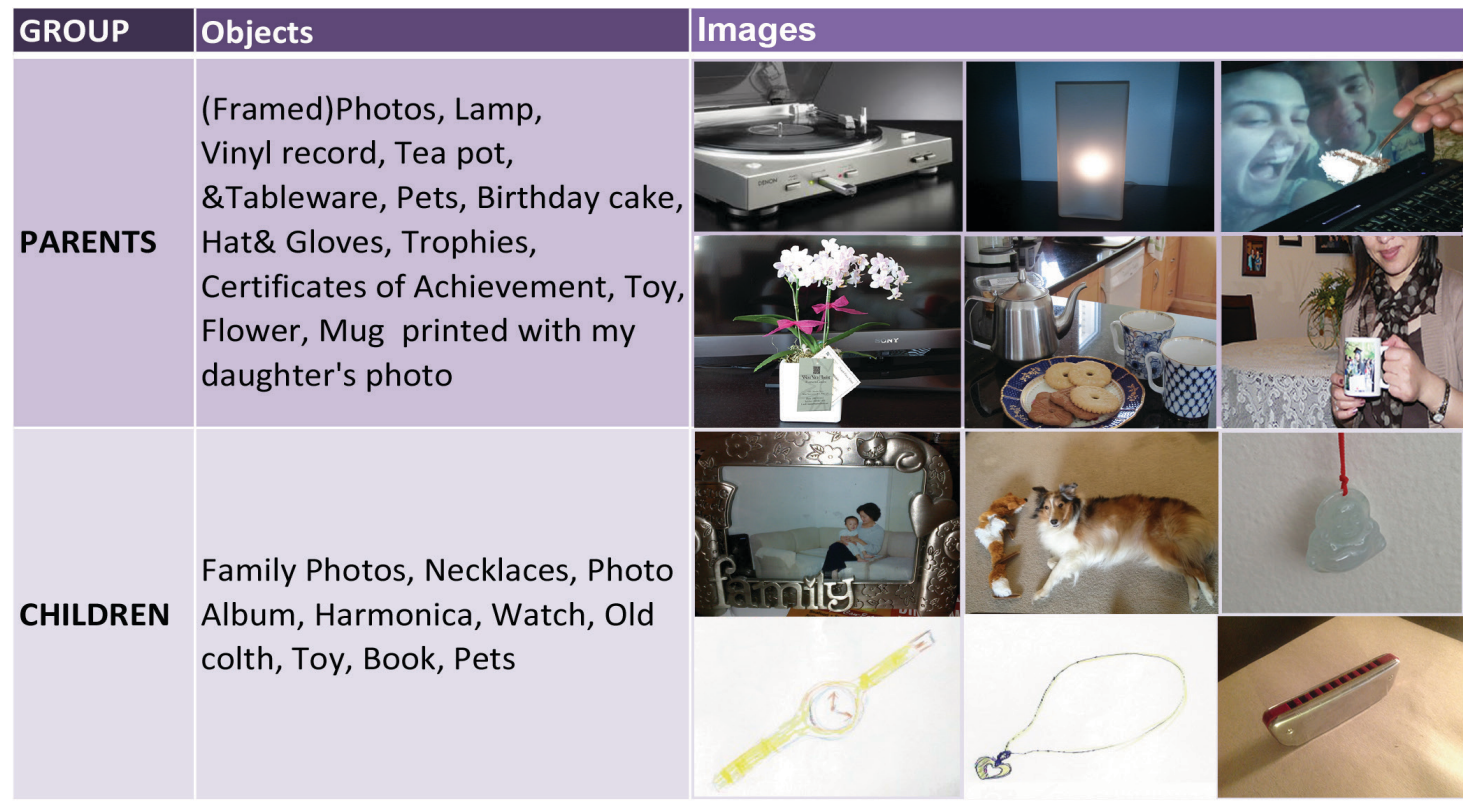

Table 8. Memorable Objects collected from parents and children groups 
This section surveyed the memorable objects associated with the children or parents in the study. The information collected included diverse types of objects as well as some special meanings the objects had in the dynamic or history of family relationships. Table 8 presents some typical answers from parent and children groups.

Family photos were one of the most frequent objects indicated in the study. Two parents and four children chose a photo to represent their memorable objects. The types of photos varied: framed, colored, black and white, photo album and photos printed on a mug. The photos in question were all physical, actual photos, not digital pictures. Additionally, the contents of the photos from the two groups were also different. 2 parents provided photos of their children from childhood, and the other 4 photos from the children group were all family portraits.

Accessories were another set of objects mentioned frequently. Four children and one parent described them as the gifts given by or received from their family members. The forms could be necklaces, watches, gloves and hats. In addition, some objects representative of the time family members spent together were also present, such as: pets, the music they shared, and some tableware.

\subsubsection{Symbols and Metaphors}

In the last section, each participant brainstormed 4 symbolic things that they associated with the sense of family. This imagination exercise collected 60 answers. Since participants understood the sense of family differently, these data were categorized into different meanings and attributes. Table 9 presents some images/examples for each category. 


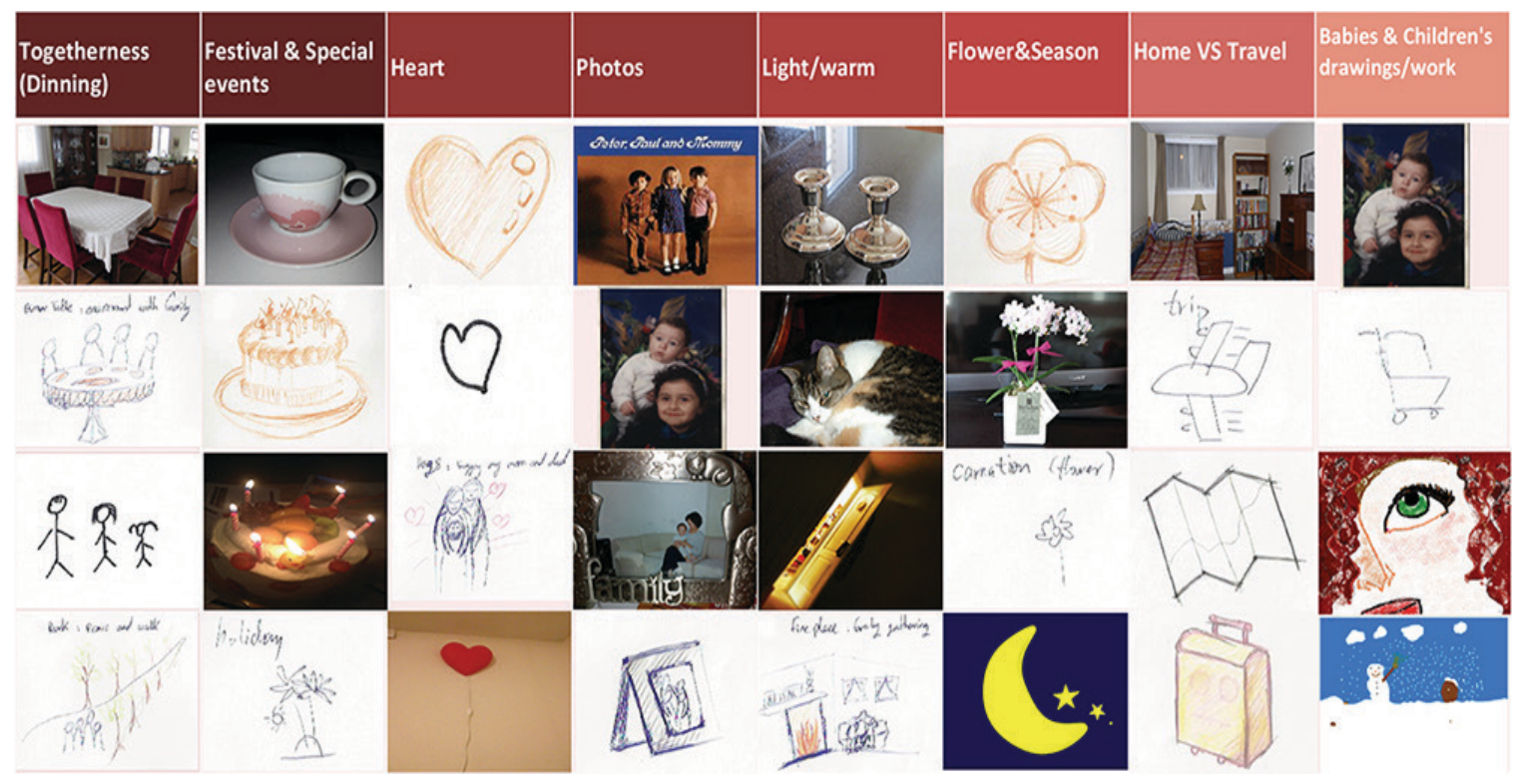

Table 9. Categories of Metaphors through the images provided by participants

The majority of answers related to family togetherness, family activities, time as representative of the sense of family. Participants also referred to holidays (events), home visits and travel as meaningful metaphors. Moreover, some physical states (e.g. light, warmth and softness etc.) and graphic symbols (e.g. photo, heart, flower and seasonal symbols etc.) could also symbolize their feelings about family and family affection. Finally, participants, especially in the parents group, stated that baby images and children's childhood pictures of their work, singing the piano, also gave them a feeling of family. 


\subsection{Workshop}

\subsubsection{Messages}

\begin{tabular}{|l|c|c|c|c|c|}
\hline Rank & Category No.1 & Category No.2 & Category No.3 & Category No.4 & Category No.5 \\
\hline Group1 & How are they & $\begin{array}{c}\text { Share our } \\
\text { emotion }\end{array}$ & Happy times & $\begin{array}{c}\text { Say something } \\
\text { at the end of a } \\
\text { communication }\end{array}$ & \\
\hline Group2 & Wellbeing & $\begin{array}{c}\text { Temporary } \\
\text { missing }\end{array}$ & Emotion casual & Events/Festivals & Blessing \\
\hline Group3 & $\begin{array}{c}\text { Express my } \\
\text { concern }\end{array}$ & Recall memory & $\begin{array}{c}\text { Togetherness } \\
\text { /connected }\end{array}$ & Physical & \\
\hline Group4 & Concern & Special greeting & Dailly greeting & expression & \\
\hline Group5 & $\begin{array}{c}\text { Personal } \\
\text { wellbeing }\end{array}$ & Communication & Events & & \\
\hline
\end{tabular}

Table 10. The categories generated from card sorting exercise and corresponding three main categories

In the first exercise of the workshop, participants categorized information based on their understanding of the properties of 13 messages; and the methods they used to prioritize categories referred to their personal preference and the sequence of communication in common sense, like which message would be used at the beginning or the end of a conversation. The results in Table 10 outlined the categories created in each group. According to the titles of the categories and their interpretations, these messages were refined to three main categories. They were: "Expressing concern \& wellbeing", "Emotion" and "Memory \& togetherness" respectively.

\section{(1) Expressing concern \& Wellbeing:}

The first type of message, graded by frequency of preference, was "expressing concern and wellbeing" above any other type of message. It tied in with the inquiries about "health" and if "everything is ok?". From the 5 groups' discussion, they all stated that "expressing concern", "asking about health" and "is everything ok" were the first things coming to mind when starting a conversation. It was the regular routine of daily 
greeting at the beginning of a conversation. This type of messages was the most preferred expression that could extend to any other sort of messages or topics.

\section{(2) Emotion:}

The second type of message was tied to expressing emotion, and they included messages like "I miss you", "smile", "kiss" and other emotions. These messages would not come up independently, but they appeared to be complementary to topics or content

during the conversation. Participants usually would report what happened through sharing emotion and moods. For instance, children would respond to their parents by sharing emotion after knowing their health status. It was noted that not all the participants were willing to share their emotions, especially bad news. However, they elaborated in their communication with intimate family members that they wanted to know more information about their relatives. A child stated: "with my parents, I rarely share my emotions with them. Especially when I'm not feeling well, so I do not want them to know that, but I would like to know about their status. I would like to find out if my mom is healthy and only then maybe share how I am and what is going on with me."

\section{(3) Togetherness \& Recalling memory:}

The third type of message was comprised of messages and topics related to a sense of togetherness and memories. Togetherness was best expressed in the time parents and children used to spend together, like a home visit, family activities and other special events. Participants prioritized this category after the category "expressing concern", since these messages were used less frequently than daily greetings. However, the group discussion indicated that "togetherness" was still an important message that helped them 
to recreate memories about family. Recalling those memories enabled participants to find the emotional connection with their family members.

\subsubsection{Objects}

In the second exercise, each group selected one or two object card(s) to develop the ideas for communicating through new tools (Figure 3). Their choices focused on wearable objects (i.e. watch, bracelet and necklace etc.) and teacups, as well as family photos and lamps.

\section{(1) Wearable:}

All five groups chose wearable types of objects for communication at least at one end of the conversation. Four groups chose to design special watches to function with their communication tasks, and two groups chose a bracelet and necklace respectively. Group 1 stated they would prefer something that would always be with their children, to make it easier and possible to reach the children anytime they want. Group 2 also chose a wearable object, because they thought the watch could be a clue for an incoming message.

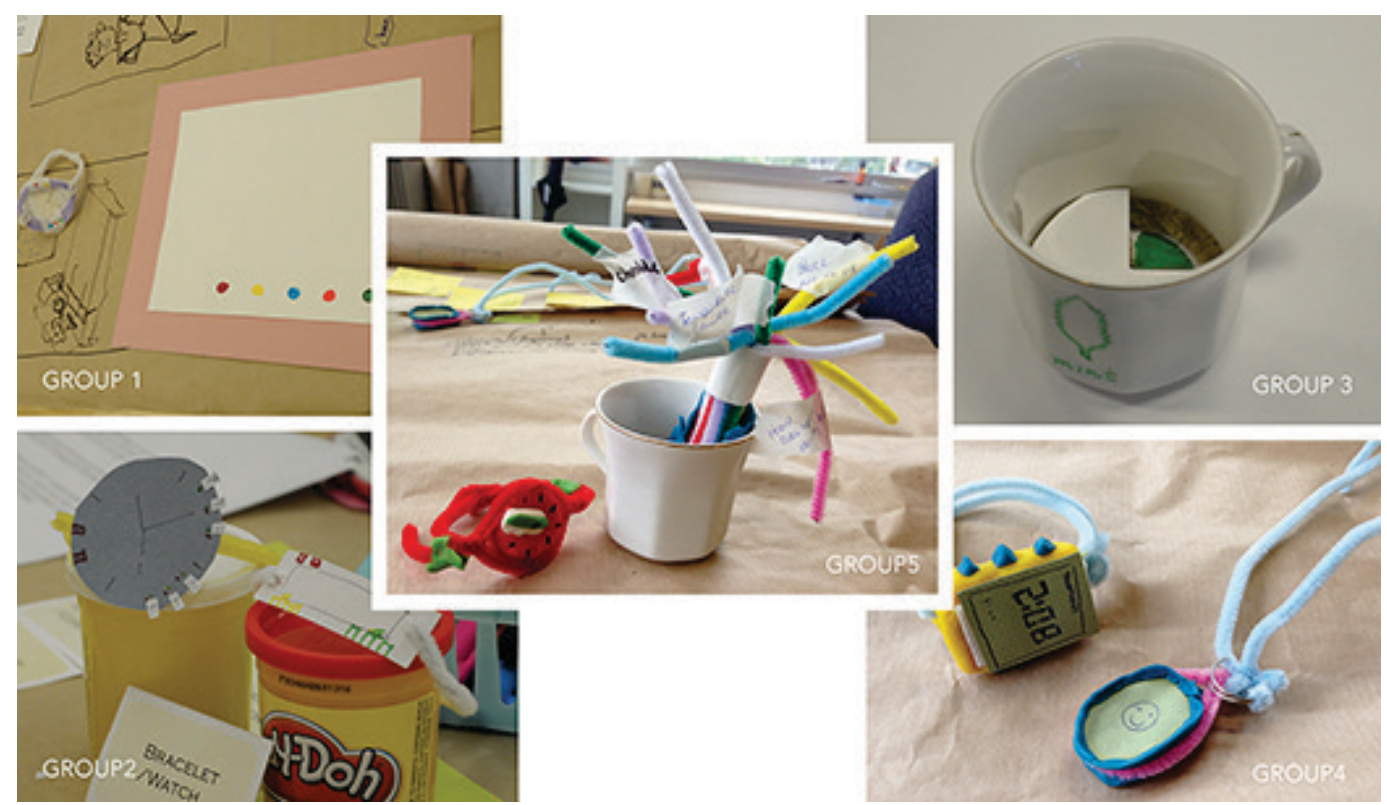

Figure 3. Object models developed by the five groups 


\section{(2) Teacup:}

Two groups were interested in the teacup. They conceived teacups not just for drinking, but also because they triggered rich meanings by association, such as togetherness and warmth. One child participant described: "when I was little, I always had mint tea with my mom. It's like remembering that time." According to the participants' imagination, different teas represented different meanings. If the teacup had a certain database to recognize these meanings, participants could share emotions, send meaningful messages, or even allow them to drink the same type of tea "together" over the distance. Therefore, they would know they are connected via drinking the same tea and knowing they might be in similar emotional states.

\section{(3) Photo Frame \& Lamp:}

Two groups selected the photo frame and lamp respectively during the workshop, and one group stated that family photos represented one of the most direct and common means to express yearning for family members. They developed an interactive digital photo frame for the parent, and used the space on the photo frame to create an interactive screen for communication. One parent stated, "Family photos have special meaning to me. They are always on my desk. If my children are not being with me, I can at least look at the picture when I miss them."

Another group developed the concept of using lamps for communication. The envisioned lamps were smaller than usual, with features that were normally only performed by wearable devices, such as sensing heart rate to share mood/status and projecting images to share sights. Specifically, the properties of color, intensity, heart rate, body temperature and ambient light were the means of the input into the lamp. 


\subsubsection{Inputs \& Outputs}

These rough models of interactive tools explored different sensory modalities in communication scenarios resulting in various potential input and output methods.

Wearable devices (watch, bracelet, necklace) and digital photo frames have similar inputs and outputs, so they are grouped in a single category. Since the teacup and the lamp had different features and functions, the teacups and lamps are allocated to the second and third category.

Table 11 presents the interaction process of these devices, covering multisensory means of interaction. In the first category, the main inputs are identified to be different types of touch. On the output side, graphical image (display/ projection), photo and video allowed participants to share the message content; vibration, light and alert sound were common output signal. These features corresponded with the devices currently on the market, such as: smart screen, buttons, camera, and projector.

\begin{tabular}{|c|c|c|c|c|c|}
\hline Objects & Inputs & $\begin{array}{l}\text { Sensory } \\
\text { Modalitie }\end{array}$ & Outputs & $\begin{array}{l}\text { Sensory } \\
\text { Modalitie }\end{array}$ & Important parts \\
\hline $\begin{array}{l}\text { Digital } \\
\text { photo } \\
\text { frame } \\
\text { Watch } \\
\text { Bracelet } \\
\text { Necklace }\end{array}$ & $\begin{array}{c}\text { Touch/Knock } \\
\text { twice/Slide } \\
\text { Writing/Drawing } \\
\text { Camera } \\
\text { Watch rotation } \\
\text { Speaker }\end{array}$ & $\begin{array}{l}\text { Tactile } \\
\text { Visual }\end{array}$ & $\begin{array}{c}\text { Vibration } \\
\text { Flashes/ Light } \\
\text { Colors } \\
\text { Graphical image/Projected } \\
\text { graphic } \\
\text { Photo/Video } \\
\text { Freehand drawing / text } \\
\text { Alert sound }\end{array}$ & $\begin{array}{l}\text { Tactile } \\
\text { Visual }\end{array}$ & $\begin{array}{c}\text { Smart screen/ digital frame } \\
\text { Bottoms (Emergency bottom) } \\
\text { Writable screen } \\
\text { Drawing tool (pencil like) } \\
\text { Camera used to share photos } \\
\text { Projector } \\
\text { Dial } \\
\text { Speaker }\end{array}$ \\
\hline Teacup(s) & $\begin{array}{c}\text { Various type of } \\
\text { Tea(i.e.Mint) } \\
\text { Smell \& scent } \\
\text { Database of Favorite } \\
\text { food/drink } \\
\text { Pouring/fillin liquid } \\
\text { Temperature } \\
\text { Dyes }\end{array}$ & $\begin{array}{c}\text { Smell } \\
\text { Tactile }\end{array}$ & $\begin{array}{c}\text { Smell \& scents } \\
\text { Vibration } \\
\text { Colors } \\
\text { Emotion Message } \\
\text { (i.e.Stressed) } \\
\text { Graphical image } \\
\text { Tea \& Name of the tea }\end{array}$ & $\begin{array}{l}\text { Smell } \\
\text { Tactile } \\
\text { Auditory } \\
\text { Visuall }\end{array}$ & $\begin{array}{c}\text { Rotating mechanism } \\
\text { (bottom of the cup ) } \\
\text { Flavor palette } \\
\text { Mesh } \\
\text { Cylinder shaped dropper } \\
\text { Dyes }\end{array}$ \\
\hline Lamp(s) & $\begin{array}{l}\text { Heart rate } \\
\text { Temperature }\end{array}$ & Tactile & $\begin{array}{c}\text { Light: } \\
\text { Intensity \& color } \rightarrow \text { mood } \\
\text { Rate/Frequency } \rightarrow \text { small } \\
\text { vital signals } \\
\text { Projector } \rightarrow \text { sharing of } \\
\text { sights } \\
\text { Shape }\end{array}$ & Visual & $\begin{array}{l}\text { Light } \\
\text { Heart rate monitor }\end{array}$ \\
\hline
\end{tabular}

Table 11. Inputs, outputs and important parts 
In the first column, Group2 (P\&C) proposed using handwriting/drawing to communicate on their wearable tools instead of digital text. The conceptual models (Group2) had the important components of writable screens and writing tools. The parent participant generated the following idea: "Think about if I wake up in the morning, the son and daughter just returning something that would show up on my fridge. That would make me happy. Like a drawing or something in their own words that I could see, and then respond with something. Almost like texting but it is more intimate and actual, or you could even see them while they are writing, and then I would feel more connected by writing there."

In the second category of the teacup, the tactile sense was less important; instead, scent and vision became the dominant sensory channels at both input and output ends, as they represented the actual meanings of the information (e.g. scents of tea or food associated with personal favourites and memories; color coded messages). In order to become functional, these types of communication through scent and visual clues were developed differently by two groups. Group3's concept was a rotating mechanism with a flavour palette and mesh at the bottom of teacups; each type of tea represented a different emotional messages (e.g. mint tea is equal to stress and anxiety; strong green tea to trying to stay with your work). The other group created a special dropper tool, which was used to drop different dyes into the teacup. Differently colored dyes represented different messages participants wanted to convey and send.

The last was the interactive lamp. Participants envisioned that measuring the heart rate and body temperature were the dominant inputs, and the outputs were lights in a variety of visual forms, including color, intensity, frequency and shape of the light. These 
properties decided the expressions of emotion or mood, as well as the sights participants would like to share by projector.

\subsubsection{Ground Rules}

Apart from the exploration of the inputs and outputs for interaction, these groups also created ground rules to explain the specific meanings of the inputs and outputs. A participant said that: "It has to have some ground rules, some initial communication prior to (starting to use these tools), and they are interchangeable or even could be reset." The significant step was to decide how to give inputs and outputs meanings that could communicate the messages, and to help the sender and the receiver understand the same meaning. It was noted that all the teams spent a fair amount of time discussing the rules, especially when they were making rough models. They used the following key elements from selected outputs to code their communication content.

\begin{tabular}{|c|c|c|c|}
\hline & Object Parts & Meanngs of Colors & \\
\hline GROUP1 & $\begin{array}{l}\text { Buttons of } \\
\text { Family photo } \\
\text { frame } \\
\text { Flashlights } \\
\text { of Watch }\end{array}$ & $\begin{array}{l}\text { Memory/ Sharing photos or make a } \\
\text { conversation with videos or camera } \\
\text { Sharing emotions/ smiley faces, } \\
\text { emotional symbols and greeting } \\
\text { Holidays/ come home to visit }\end{array}$ & $\begin{array}{l}\text { Express my concern } \\
\text { Emergency button/ } \\
\text { Call me now }\end{array}$ \\
\hline GROUP2 & $\begin{array}{l}\text { Buttons of } \\
\text { Watch/ } \\
\text { Bracelet }\end{array}$ & $\begin{array}{l}\text { Questions } \\
\text { Answer/ Express feelings }\end{array}$ & \\
\hline GROUP5 & $\begin{array}{l}\text { Dyes of } \\
\text { Teacup } \\
\text { Dropper }\end{array}$ & $\begin{array}{l}\text { Peace/all is ok } \\
\text { How are you doing } \\
\text { Chocolate }\end{array}$ & $\begin{array}{l}\text { Trees and fresh air. } \\
\text { Kiss } \\
\text { Ken's favorite flower scent } \\
\text { Cinnamon }\end{array}$ \\
\hline
\end{tabular}

Table 12. The examples of Color-coding

Color-coding was one of the frequent means to set ground rules. Particularly, Groups No.1, 2, 5 coded their messages in different colors (Table 12). For example, 
Groupl designed five buttons to support different functions on their photo frame and watch. Group 2 designed 2 buttons to code "sending" and "responding" menu for the watch and the bracelet: Blue for Questions; Red for Answer/ Express feelings. Similarly, Group 5 used different dyes for the magical teacup and lighting points on the watch representing different interpretations. For instance, "Yellow" meant peace/ "All is ok", and "Pink" was "How are you doing?"

The idea of using magical teacups for communication developed from Groups 3 and 5. These two groups used scents to symbolize the messages they needed. Group 3 used different types of tea to represent emotional states. Group 5 chose the scents from one's favorite food or favorite scents (e.g. cinnamon, Ken's favorite flower scent and fresh air etc.). These rules were created based on their personal experiences, in which the family stories and memories were associated with certain scents.

In addition, Group 4 (C\&C) used graphic images to code messages. For example, they interpreted a tree image as meaning "health", where the appearance of a tree in different seasons was used to represent someone's state of health. For the concept of the interactive lamp, Group 3 used the change of heart rate to code different moods or statuses, by rising higher or going down.

\subsubsection{User Scenarios}

Based on the interactive tools and concepts that the five teams developed, they finally created the stories behind using these tools. These scenarios presented in Table 13 describe the process by which parents and children would interact with each other via those new objects. It became evident that wearable objects constituted the most popular 
of interaction among these groups, with, for example, 4 groups choosing watches to

represent the children's side. By comparison to the children's selections, parents used a

\section{larger range of artifacts for communication.}

\begin{tabular}{|c|c|}
\hline \multirow{2}{*}{ GROUP1 } & \\
\hline & $\begin{array}{l}\text { WATCH } \\
\text { 1. The son is sick. He presses the green bottom; } \\
\text { 4. either the mother calls the son or the son calls his } \\
\text { mother. They start talking; } \\
\text { 6. They solve the problem, ...happy ending. }\end{array}$ \\
\hline GROUP2 & $\begin{array}{l}\text { WATCH } \\
\text { 1. The son wakes up in the morning and he is thinking of his } \\
\text { mother. He sends his mom a message 'how are you?' } \\
\text { 3. So he sends a message on her bracelet. It could be a little } \\
\text { image, a flower, a drawing or whatever he wants to send; } \\
\text { 5. He uses the camera to take a picture of his transcript, } \\
\text { 'hey!, I got a At'; }\end{array}$ \\
\hline \multirow[t]{2}{*}{ GROUP3 } & $\begin{array}{l}\text { 1. It's 11clock at night, and the daugter has an exam next } \\
\text { day. She is extremely anxious about this exam, and she } \\
\text { can't get to sleep. she just had idea... 'I am going to make } \\
\text { tea'. } \\
\text { 2. The bottom of the cup has a rotating mechanism, so she } \\
\text { is able to input different type of teas (e.g. mint). The teacup } \\
\text { displays an image of the tea; } \\
\text { 5. At the end, they drink mint tea over long distance } \\
\text { together. }\end{array}$ \\
\hline & WATCH \\
\hline
\end{tabular}

2. When the son is checking time, the watch rings/ vibrates. He receives the message from his mom. The watch projects a smiley face on the closed table;

3. He knows that his mother is missing him. So he touchs the screen twice, and sends her a green tree image (which means that 'everything is ok'. 'I'm very healthy')

\section{WATCH}

3. Ken receives the message that the pink flashlight is blinking. He smells something, and he knows that his mother is cooking his favorite food.

4. He rotates the needle to the yellow point ('All is ok'), and sends back a message to his mom;

\section{PARENTS}

FAMILY PHOTO FRAME

2. His mom receives the message. The photo is flashing so she knows something has happened to her child;

3.When she presses the botton, she gets a sick face, so she knows the son is sick. Then she presses the blue botton;

5. The mother asks the son to take some medicine;

\section{BRACELET}

2. She gets the message from her son. She is not feeling wel because she misses her son;

4. Getting it makes her feel a little bit better so she sends

him 'she is feeling better'. And then, she sends him back a question asking him about his studies.

6. She sends him back a smiley face as a easy way to start a day.

\section{TEACUP}

3. Mom has the same cup with the same mechanism. To hear that, she is boiling mint tea to relax to get to sleep, and right away she understands that she is' $\mathrm{Oh}$, anxious'; 4. There is a display on her cup, so right away she calls her daughter and they talk (Child:'I'm really anxious about the exam'. Parent: 'don't worry about it. It's fine'.)

\section{NECKLACE}

1. The mother misses her son. She slides the screen of the nacklace;

4. Her necklace vibrates and alerts. The nacklace lights up, and she sees a green tree projected in the front. So she knows that the son is ok.

\section{TEACUP}

1. I'm cooking my dinner. I'm thinking that this is Ken's favorite food. 'my child will like this';

2. I send him the 'pink' message (-How are you doing today) by dropping a little pink dye in the teacup;

\section{Table 13. User scenarios}

It was interesting to note that while participants were using the tools they

developed to communicate, they did not give up traditional means of communication like 
the phone call. In Group 1 \& 3's stories, they used new artifacts to convey brief messages at the beginning of a connection. In the later stories, once they received the messages and knew there was something wrong or something happened, they preferred to call each other to inquire about further information or give more suggestions. In these stories, while children were sick or feeling anxious in certain situation new tools could make a connection and alert parents that something had happened. Then, they would talk to each other by phone.

\subsubsection{Comparison}

\begin{tabular}{|l|c|c|c|}
\cline { 2 - 4 } \multicolumn{1}{c|}{} & PARENT & CHILDREN & IDENTICAL FEATURES \\
\hline Group1(P\&P) & Family Photo Frame & Watch & $\begin{array}{c}\text { Color Buttons } \\
\text { Color code Messages }\end{array}$ \\
\hline Group2(P\&C) & Bracelet & Watch & $\begin{array}{c}\text { Color Buttons } \\
\text { Color code Messages } \\
\text { Hand WritingFunctions }\end{array}$ \\
\hline Group3(C\&C) & Teacup & Teacup & $\begin{array}{c}\text { All Identical Components } \\
\text { Inputs \& outputs }\end{array}$ \\
\hline Group4(C\&C) & Necklace & Wamp & $\begin{array}{c}\text { Graphic Messages } \\
\text { \& Scents }\end{array}$ \\
\hline Group5(P\&C) & Teacup & Watch & $\begin{array}{c}\text { Color code Messages } \\
\text { \& }\end{array}$ \\
\hline
\end{tabular}

Table 14. Asymmetrical and Symmetrical features of the objects between parents and children

Finally, the differences and similarities of these tools from the perspective of both older parents and young adult children were compared (Table 14). By comparing the choice of objects, it was found that 4 groups chose different objects for senders and receivers, and only one Group (C3) chose to use identical tools at each end. Even though, within one pair of workshop participants, individuals chose diverse objects, the communication modes still appeared as a symmetrical pattern. Two different tools (i.e. Group5's teacup 
and watch) in a pair still had the same features and functions. It was observed that participants preferred to design the interfaces in the same way.

This similarity was found in participants' conversation as well. When Group 1 was making the models, they stated: "It has to be the same buttons and same colors. It is a digital and smart watch that it has a big screen with buttons. They are the same as we have in the photo frame"; and Group 4 also stated: "The method of communication is the same. They can switch the objects if they want". In the same case, when Group 5 generated the concept of the magical teacup, they also assumed that the other object (watch) on the children's side would have the same functions. Apart from the similarity of physical features, Group 3 stated: "It is just like you can drink exactly the same tea the other drinks, or just give the mood of the book they are reading. That is sharing someone else's emotion". It indicated that the teacup could be a useful item for communicating emotions and experiences. 


\section{CHAPTER 5. ANALYSIS \& DISCUSSION}

The previous chapter presented two sets of results from the diary study and the workshops. The first part primarily explored the themes and methods related to remote family communication activities, and memorable objects and metaphors associated with family membership. Inspired by the elements explored in the Diary, the second part refined the themes and messages conveyed in communications and presented the concepts of new interactive tools developed by the 5 groups.

This chapter is structured into four main sections. The first section analyzes the characteristics of memorable artifacts collected from Diary data and makes a comparison between these objects and conventional communication devices. It frames the question and prepares materials for further investigation in workshops. The second section provides a discussion of the important factors of the newly imagined tools in supporting remote interaction. The third section presents a conceptual framework through integrating the findings from the previous two sections, thus helping to address the research questions in this study. The final section discusses the limitation of this study.

Moreover, the content analyzed in this chapter refers to the multi-sensory design approach suggested by Schifferstein (2011) in literature. It follows the framework involving understanding emotional information, expressions, the associations and sensory properties; understanding the relationship between expressions and sensory properties; organizing a mind map of the information; and developing user-interaction scenarios. 


\subsection{Diary Study}

\subsubsection{Analysis of Artifacts}

This section analyzed the memorable objects collected from the Diary study from two aspects: the properties of interaction and the emotional meanings in a family context.

(1) Dynamic objects:

\begin{tabular}{|c|c|c|c|c|}
\hline & \multicolumn{2}{|c|}{ Sensory stimuli } & \multicolumn{2}{|c|}{ Sensory stimuli } \\
\hline Lamp & Switch: ON/OFF & Touch & Light: on/off & Visual \\
\hline Flower & Watering & Touch & Blossoming & Visual \\
\hline Watch & Body motion & Touch & Dial, time change & Visual \\
\hline Tiger toy & Hug and touch & Touch & Open/close arms & Visual \\
\hline Photo Album & Opening/Closed & Touch & Photo & Visual \\
\hline Birthday cake & Lighting /Blowing out candles & Touch & Light: on/off & Visual/ Taste \\
\hline Tea pot and China cups & Filling liquid and Placing food & Touch & Temprature: high/low & Taste \\
\hline Mug & Pouring, holding & Touch & Tempreture: high/low & Touch, Taste \\
\hline $\begin{array}{l}\text { Vinyl record/ } \\
\text { played record turntable }\end{array}$ & Playing, singing and dancing & $\begin{array}{l}\text { Auditory } \\
\text { Touch }\end{array}$ & Music/Sound & Auditory \\
\hline Harmonica & Playing instruments & Touch & Music/Sound & Auditory \\
\hline
\end{tabular}

Table 15. Examples of Dynamic Objects

The data collection included a number of memorable objects as indicated in the participants' diaries. According to the descriptions of the appearance/components and the way participants interacted with these objects, a group of objects were found to differ from another through their dynamic and interactive properties. These objects may have multiple sensory inputs and outputs during the interaction process. Table 15 summarizes the inputs and outputs corresponding to each object. As shown in Table 15, although outputs of those objects vary, the inputs are consistently controlled by the tactile sense that could be the dominant sense to initiate an interaction. The different outputs are 
expressed in different sensory experiences such as: visual, auditory and taste. These dynamic objects imply that there are a variety of novel inputs and outputs that could be explored for new forms of interaction.

(2) Togetherness and Memories:

The observation shows that various forms of artifacts all convey the meaning of togetherness and appeal to memories, as the time to be together. The sense of togetherness generally can refer to the physical togetherness (Grivas, 2006; Sallnäs, 1999) in an intimate family relationship. The memory of past common activities is associated with being with the family in the present via particular artifacts. In one parent's journal, the teacups represented teatime, treats and conversations during afterschool activities or when the children visited home, therefore the teacups became part of the memories that this parent has with her children. Also, family photos could remind them of the times they spent together and the places they have seen together; thus they could be considered as a common communication medium to maintain a presence (Dalsgaard et al., 2007; Chang et al., 2001; Wong-villacres \& Bardzell, 2011).

There are also some objects mentioned which were found not to belong to any other types of the artifacts mentioned above; however, they also had personal significance, bringing forth images and feelings of togetherness and memories, such as a pet. A parent and a child talked about their pets and the time their pets spent as part of the family. In another exceptional case, a child introduced a piece of old cloth she slept with every night, because it was given to her by her mom and was used to wrap her after her birth. 
(3) Blessing \& Wishes:

Among these memorable artifacts, we found that some of them implied the subtle meaning of blessing and making wishes. These artifacts are usually used in the case of people belonging to a certain cultural background or religious beliefs. In a parent's description, a lamp does not just convey the meaning of lighting, but was also interpreted as meaning a blessing for safety. When family members are away from home, a lamp can be used as a lighting candle to pray to God for protection of the children. Similarly, some children mentioned the jade jewellery that their parents gave them as gifts when they left home and started a journey, which also carried the meaning of having their parents' blessing and good wishes. It implies that wearable objects can effectively tie with interpersonal meaningfulness (Adamson, 2007; Wallace and Thieme, 2012).

\subsubsection{Analysis Model}

Figure 4 presents an analysis model to organize a mind map of the information, which is proposed as one of the important steps in the multi-sensory design approach (Schifferstein, 2011). The data collected in the diary study can be grouped into several categories: the themes, emotional expressions, input/output that come from communication activities and the meanings associated with memorable artifacts and metaphors outside of these activities. By conducting a systematic analysis of these categories, it is able to understand the interconnection between each component in a communication system. The analysis starts by comparing the conventional communication tools and the memorable artifacts. By comparing the information (messages, the corresponding meanings conveyed) and the physical interaction (inputs and outputs) of these two categories, the possibilities and potential for creating new tools 
for remote emotional communication are explored (as shown in Figure 4). This model can help generate questions and materials for further investigation.

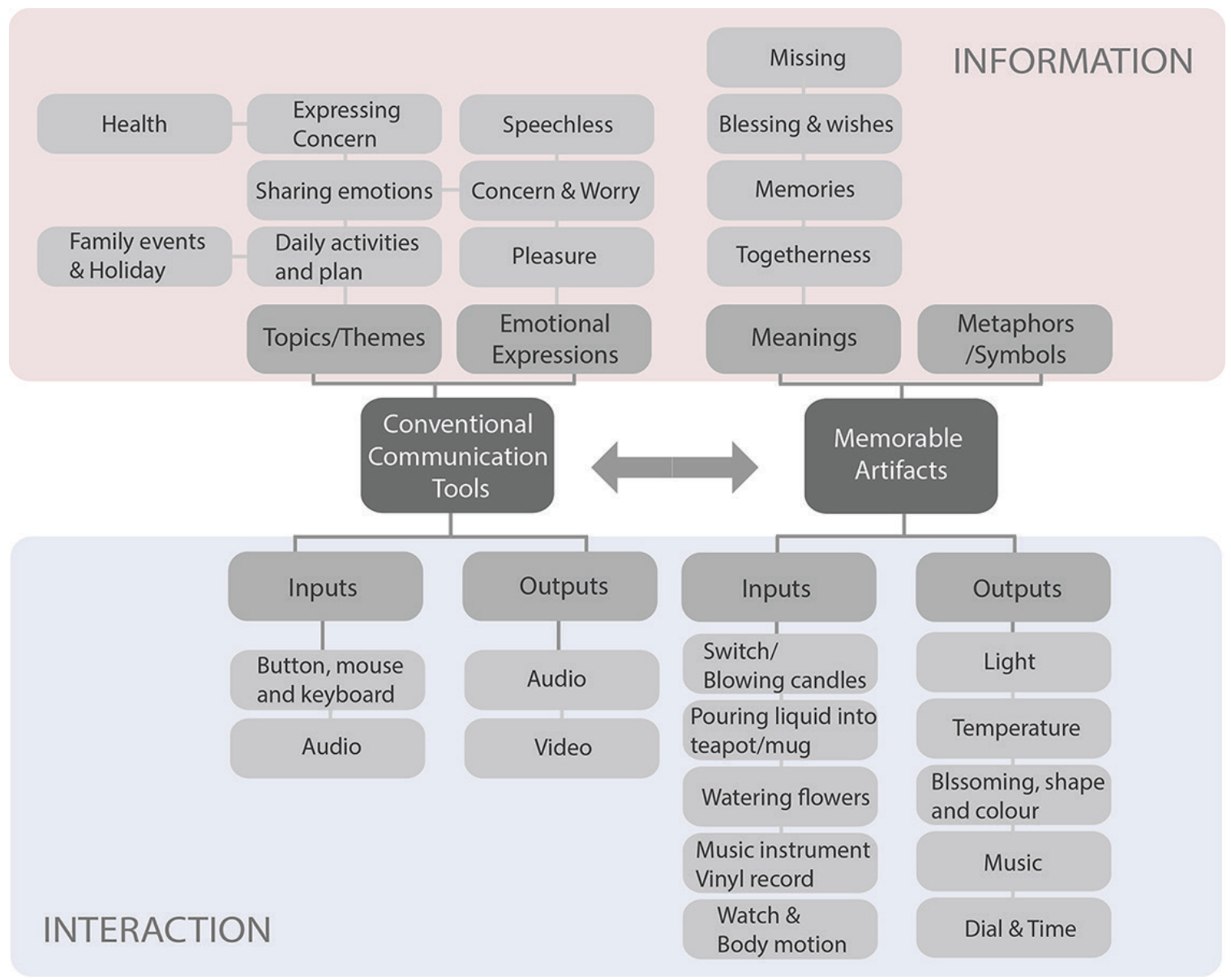

Figure 4. The analysis model: a comparison between conventional tools and memorable artifacts

\section{(1) Comparison of Information}

The results of the communication activities help identify the topics and themes emerging from family communication, including greetings, expressing concern, and discussing daily activities and plans. They indicate that conventional communication tools are more prone to convey the practical and real-time messages and topics. At the same time, instant messaging tools with emoticons and video functions also allow 
participants to share some emotions in conversations (e.g. sending a smiley face or kiss icon).

Moreover, the data from the analysis of emotional expressions implies that both parents and children like to express positive and neutral emotions in conversations. However, data also includes expressions of concern and worry when participants were unable to acquire enough information about family members. Some moments in a conversation might be speechless, since verbal communication was found inadequate to express all their concerns and emotions (Frijda and Mesquita, 1991; Dalsgaard et al., 2006). That may infer that non-verbal information may also be part of a phone conversation.

In traditional means of communication, memorable artifacts are absent and isolated from people's current communication behaviors, just like how Holman \& Vertegaal (2008) observes that digital interaction is lost in the things that could be done with other real-world tools. The artifacts are normally associated with and given particular meanings referring to past routines kept in memory but would not necessarily be present in daily communication scenarios. These artifacts carry affective meanings of togetherness, memories, blessings, or special events, which are more in-depth and personal information. Nevertheless, these affective meanings are less communicated in daily communication.

Currently there is no connection or relationship between communication tools and memorable artifacts as they carry different types of information. Memorable artifacts are driven by those more subliminal messages (memories and togetherness), which are important in making family members feel more connected. However, people primarily 
communicate more about physical activities via the communication tools available in their lives, and that diminishes the importance of emotional communication, by placing less importance on exchanging personal feelings about one another,

\section{(2) Comparison of Interaction Processes}

The analysis compared the interfaces and methods used during interacting with conventional communication tools and memorable artifacts. The typical examples of physical components and sensory properties are grouped into the corresponding categories of inputs and outputs. Figure 4 indicates that the inputs and outputs of conventional communication tools are quite consistent. Touch is the dominant sense for controlling input (i.e. bottoms, switch and mouse), and auditory and visual senses (i.e. speaker and screen) are the dominant sense for controlling outputs. By comparison, the inputs and outputs of memorable artifacts are diverse, they have various forms and interfaces to interact with, and it is found that some dynamic objects could have multiple types of inputs and outputs.

The analysis above points to the gap between traditional communication devices and memorable artifacts. Personal attachment and emotional content appears to be not easy to convey directly through more traditional forms of communication. Meanwhile, some forms of affective communications seem to be missing in more modern forms of communication, but the communications is enriched by the presence of memorable objects. As a consequence, the latter present an opportunity to explore a new communication model, new potential communication tools, all inspired by and even including those memorable artifacts. It might be an alternative way to enhance remote family connections and enhance the emotional experience. 


\subsection{Workshops}

\subsubsection{Messages}

As a result of the card sorting exercise, the three types of important identified information are summed up in the following scenarios: "Expressing concern \& wellbeing", "Emotion" and "Memory \& Togetherness". In particular, expressing concern and being concerned about well-being, were found to be the basic purpose for interactions between children and parents. In addition, they continued to be important messages conveyed in the communication activities, even if they were expressed at a superficial and basic level at the onset of a contact.

Another type of information refers to what can be grouped into the theme of "Memories and Togetherness" content that is more in-depth and personal. Participants did not place this category on top of the list, before the first category, because current means of communication do not emphasize memories. Based on the findings and reviews, togetherness and memories bring people closer together, because by recalling such memories and by sharing similar sensory experiences family members feel more connected. This is similar to the meaning of intimacy Grivas (2006) refers to, as experiencing a feeling of physical togetherness. Sharing similar scents, tastes and surrounding sights could enhance the sharing of those messages.

On the other hand, expressing concern and sharing memories provided people with the preconditions for sharing emotion and perceptions. People were unable to share some emotions due to the limitations of current communication methods, or they preferred not to exchange some emotional information so that family members would not worry about them. 
Overall, these three types of messages interconnect, and illustrate a regular pattern of family remote communication scenario. An ideal complete communication scenario would comprise: expressing concerns, recalling memories, and sharing emotions.

\subsubsection{Forms and Features of Interfaces}

Through participation in the process, the participants chose the objects in the brainstorming section of the workshops and also identified the portability, accessibility and selectable properties as important factors to consider. Portability and accessibility would allow participants to communicate without the limitations of time or location. Particularly mobile devices are suitable to support the sharing of personal information (Willis, 2012). The group discussions indicated that watches and other wearables were chosen most frequently because they are portable and accessible. Moreover, since participants felt comfortable operating interfaces that had selectable features, it was important that the designers consider this factor and incorporate it within wearable devices, such as a watch with multiple optional selectables. The interface should provide clues for performing sending or receiving tasks as well. These properties meet the needs for developing intimate computing appliance that are contextually appropriate and could respond better to users' needs (Bell et al., 2003).

Two other groups generated the ideas for making magical teacups and one group generated the idea for making family photos frames, as possible means to convey the message of "togetherness" and "recalling memory". In designing new tools in the workshops, togetherness and recalling memories could be an essential part of the emotional long distance communication Further, from the observation of the two groups' discussions, mealtime or teatime past experiences were found as inducing the creation of 
memories associated with togetherness. Using tableware like teacups can possibly evoke similar sensory (scent) experiences of those memories, which might create an invisible connection with or elicit an emotional response from a family member.

\subsubsection{Evaluation of Inputs and Outputs}

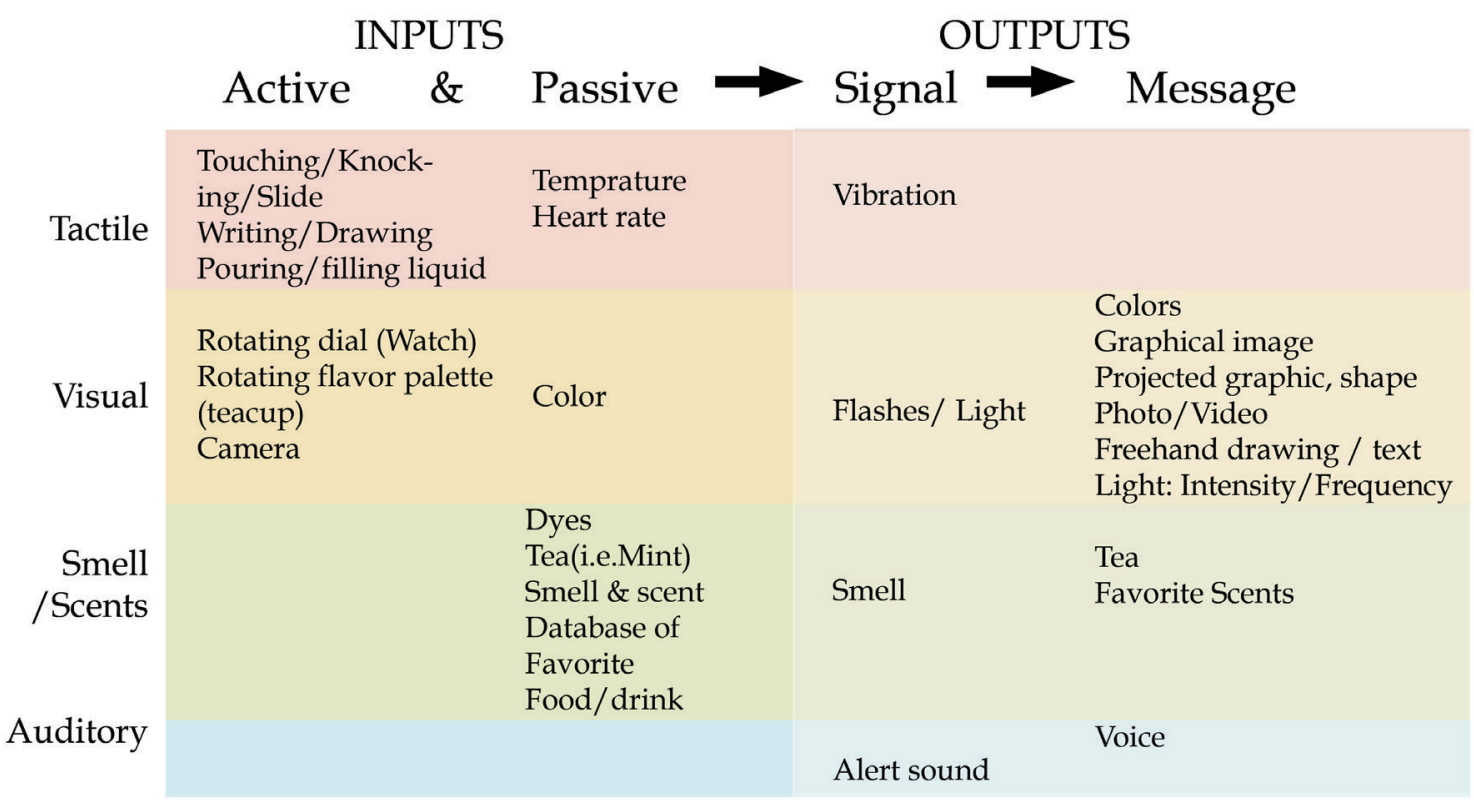

Table 16. The Categories of Inputs (Active and Passive) \& Outputs (Signal and Messages)

Inputs and outputs in general provide more information for analyzing the features of these conceptual models and the remote interaction process. These inputs and outputs could communicate through related sensory channels (Planalp, 1999). By analyzing the nature of inputs and outputs in the dimensions of sensory modalities (vision, touch, auditory and smell/taste) and their relevant roles, two types of inputs are defined: active and passive, as well as separate the types of outputs used for presenting signals and actual messages.

According to the analysis in Table 16, active inputs are the actions participants do to trigger a contact, like touching a button, writing and pouring liquid, they are usually 
completed by a single person at the initial stage of a communication. In contrast, passive inputs do not need people's active involvement, they are more like experiencing some physical properties of the objects themselves, sensed by devices, such as body temperature, heart rate and scents etc. The comparison between the two types indicates that active inputs concentrate more on the tactile sense; but passive inputs have more variations that distribute across multiple senses.

Also, the outputs could convert into two categories based on their roles and the communication order. The initial outputs send the recipients signals that are necessary requirements to establish a connection. This type of output is noticeable or visible by the receivers. In this study, participants identified (or chose) some signals like vibration, flashlight, and alert sound, which are relatively common and already exist in traditional devices. Another type of outputs represents the actual messages sent to a terminal. These appear to be more varied by comparison to the signal outputs, using features such as: image, color, freehand drawing and favorite scents. Tactile sense is missing in this part of the process. Instead, vision and smell are the dominant senses associated with these messages. For instance, the project from Group 2 identified that freehand writing and drawing were more important outputs for helping people feel closer to each other as compared to digital text and graphics,

Table 17 presents the roles of each sensory stimulus in such interaction processes. Touch plays a dominant role as an input. There are diverse actions that could enable people to initiate a connection to each other. Nevertheless, these tactile inputs would eventually convert into other types of sensory outputs to present the actual message. 
Vision and smell could also be more closely tied to the output aspect of an object than touch.

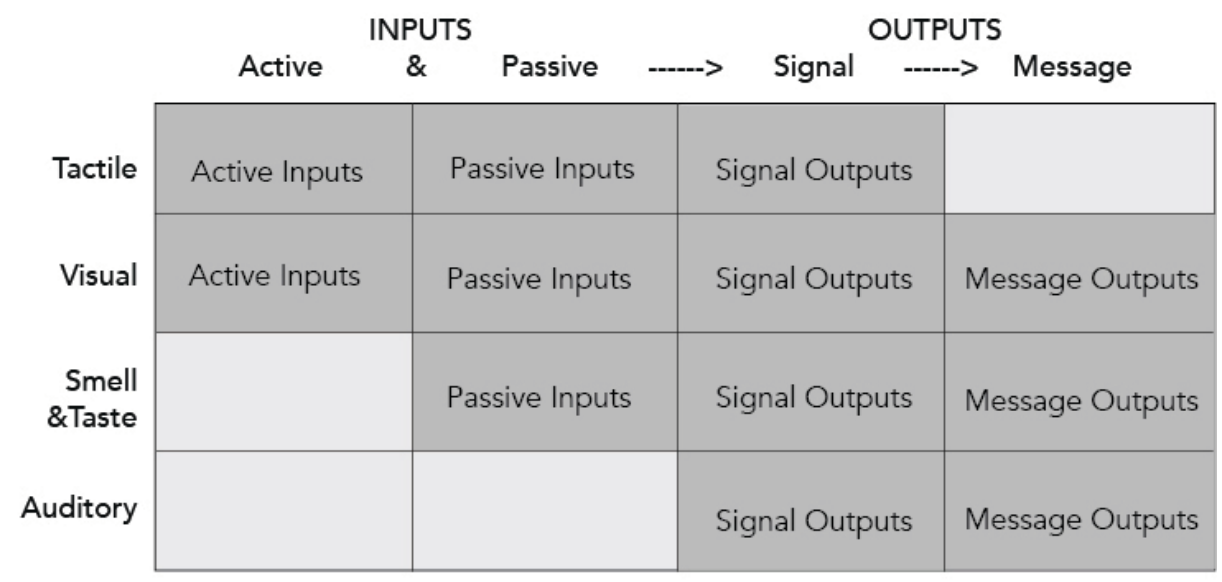

Table 17. Sensory Mapping

Vision is the most direct way to receive information in diverse forms such as:

colour, shape and image. It is noted that the participants were good at applying colours to implement their ideas, because colours are selectable and distinguishable, thus allowing participants to easily code the message with meanings they wanted to convey. In other words, an ideal interface for a communication tool requires selectable properties in order to present different messages in different scenarios. The diversity of visual outputs could meet such design criteria.

Moreover, the models of the novel teacup revealed the potential association with the sense of smell. It informed the author that aside from the dominant sense of vision, there is also possibility to explore other new types of sensory stimuli to enhance emotional experiences over long distance. Even though scents seem subtle and invisible, they have strong connections to personal memory identification. The magical features about scents that have been explored in this study could constitute alternative means for sharing emotion, statement and making people feeling more connected. 
Last, the auditory sense is not identified as much as the other senses. Only a few groups in this study mentioned the talking functions and alert sounds and they were similar to from conventional means of communication, like the telephone and other instant communication tools primarily driven by verbal communication. This observation shows that participants successfully detached from traditional verbal means of communication in the workshops, and were able to explore possible non-verbal interactions.

\subsubsection{Metaphors}

The process of communicating messages also involved communication through metaphors, as metaphors enabled people to attribute meanings and emotions to artifacts and mediate intimacy (Krippendroff, 2006; Vetere et al., 2005). Meaningful metaphors could be communicated through certain sensory inputs and outputs. Based on the results from the study, it was found that most of the metaphors were conveyed via visual modalities, and some of them were associated with the sense of smell, such as tea and personal favorite foods/scents.

The study also reveals that participants preferred to use metaphors that have more variations, which could represent the message in different conditions. For instance, a children team used the graphic of a tree to symbolize different states of health. When they would express concern over the parents' health, parents would respond by showing different colored trees. Additionally, emoticons were found to be the most familiar method used in current devices, therefore participants liked this straightforward way to share emotions or showing different self-status, using emoticons such as: a smiley face, a sick face etc. 
Further, the nature of these metaphors was different. Some of them were in the conventional sense that could be understood by the general group, such as heart, flower or kiss. Especially flower was used frequently in three groups' scenarios. On the other hand, the other set of symbols were more related to personal attachments that might not be reasonable for everyone. They are based on particular experiences, memories or personal preferences. For instance, parents feel more connected to their children by communicating with their children's freehand writing/drawing, because they are familiar with this handwriting; or like the tea or the scent from someone's favorite food, which they associate with personal memories of being with family.

\subsubsection{Communication Pattern}

Based on the choices of objects, features and ground rules discussed above, these factors are compared for both the parents and children's sides. There appears to be a regular communication pattern that consists of both symmetrical and asymmetrical characteristics. The pattern could contribute to creating a guideline for the design of paired communication tools. It would serve to better understand what factors should be identical or distinct.

Participants tended to create a pair of devices (Parents' and children's) with the same or similar features, and they did not differentiate the functions for parents' and children's sides, revealing a symmetrical aspect of the device design. In the cases of five user scenarios, the interaction methods from the two directions could be reversible. This fact informed the study that there was no evidence to support the idea that different generations have different demands in communication. The similar features also 
established a ground rules connection, making it easier to understand by both groups and each other.

On the other hand, even though the features designed were more likely to be similar, the forms of the paired artifacts could be diverse. That meant completely different artifacts could be placed in a pair. We observed that the participants were flexible in terms of the choice of a pair of tools; they thought the objects should not necessarily be the same. In most cases, participants in one group had different perceptions and personal preferences, but the final decision making process was usually a compromise between two persons' ideas.

\subsection{Discussion of Research Question}
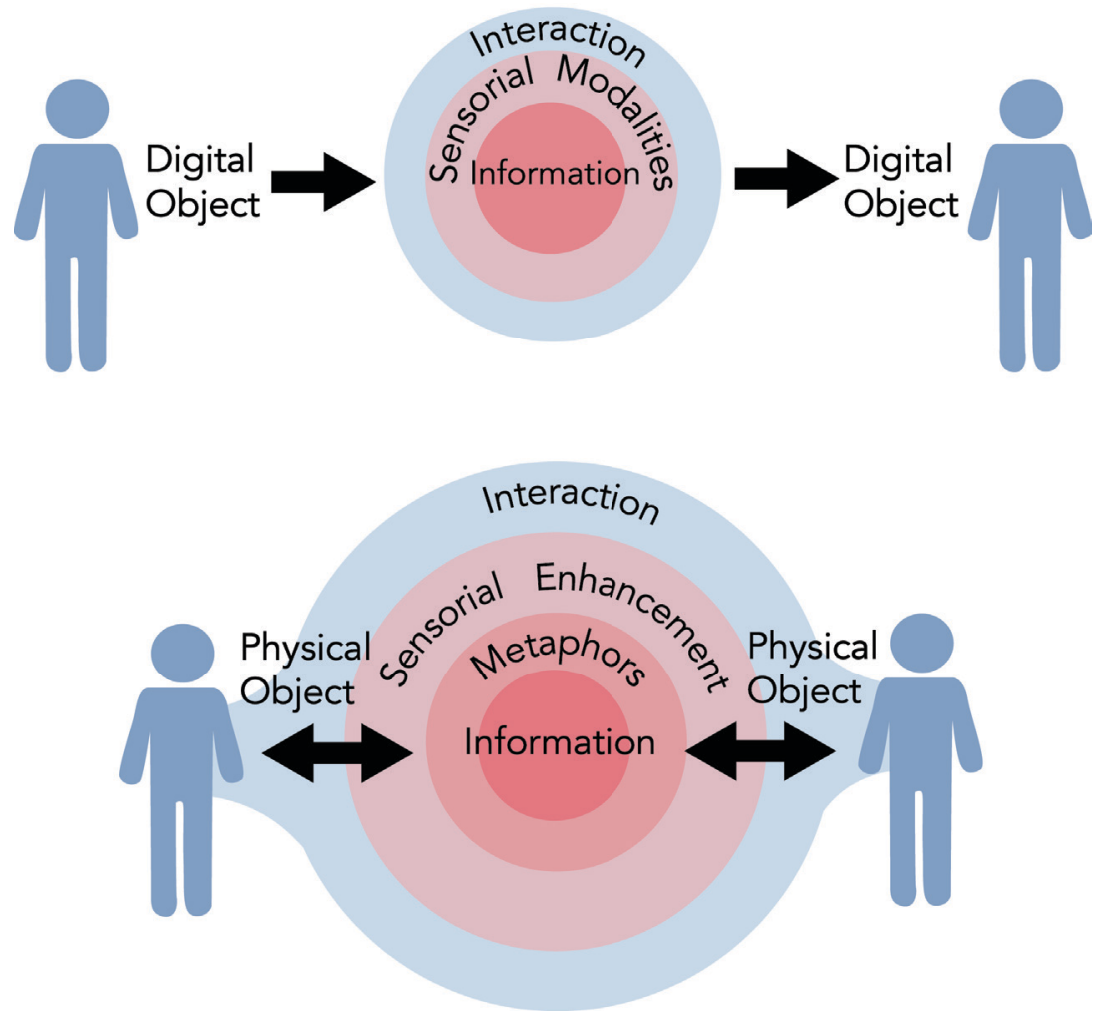

Figure 5. Conceptual models of remote interaction with digital (top) and physical (bottom) objects 
The conceptual models above illustrate a general process for remote intimate sensory experiences through interacting with the aspects being investigated in this research. The top of Figure 5 describes the interaction with digital tools, which cannot enhance intimacy due to the lack of layers for delivering emotional content. The bottom part illustrates the use of physical objects that add richness and diversity and additional layers around the information, which might provide the possibility to enhance the feeling of remote intimacy. This pair of models helps to answer the research question about how the users' perceptions and activities can support such experiences through interaction with physical and digital objects using metaphoric imagery.

\section{(1) There is a design opportunity for alternative means of communication that enable} people to share positive expressions in remote intimate communication.

This study has revealed that the general characteristics of remote emotional communication between young adult children and their parents are: happy, neutral and positive. Thus, they are more likely to share positive emotions with each other in a general context. These qualities affirm the positive meaning of emotional communication experience in influencing family relationships and that the social connections between children and their parents are vital for the well-being of family members (Dalsgaard et al., 2007). This fact should inform designers to be more aware of developing new methods for sharing positive expressions in remote interaction.

Except the use of graphical emoticons, this study collected a number of metaphors associated with family feeling and some emotional expressions. For instance, they could generally reflect the positive meanings of togetherness, warmth and smiling. They could also be an effective symbolic language to convey the information about "if everything is 
ok", such as light indicating that someone was at home and manifest the presence of life (Tollmar et al., 2002) and weather metaphors that could interpret a family member's health and living situation. These metaphors indicate that there is an opportunity to explore different sensory means for sharing communicators' positive feelings.

\section{(2) Conventional communication methods cannot convey all types of information; in} the future they could be enhanced by different sensory means of communication.

The literature review established that current technologies do not seem to support remote emotional and intimate communication adequately, since they do not allow people to fully express their intended thoughts or feelings (Keng et al., 2009, Willis \& Jones, 2012; Smith \& MacLean, 2007; Werner \& Hornecker, 2008). This research supports those findings through comparing the messages tied to conventional tools and memorable artifacts. The study results indicate that conventional means of communication cannot transmit all types of messages.

First of all, conventional means offer the opportunity to share more concrete meanings and physical content, including greetings, expressing concern, and discussing daily activities, but miss those more personal and emotional information, like the theme of "Togetherness and Memory". This theme relates to the meaning of intimate experience in the sense of physical togetherness, which has been used to define intimacy and presence in literature (Grivas, 2006; Witmer, 1998). However, it has also been found through association with memorable artifacts rather than digital devices.

Second, the investigation of emotional expressions identified some "concerned", "inquiring" or "speechless" signals in communications, which reveals the non-verbal 
properties of family communication. Remote intimate sensory experiences are constructed with not only verbal communication but also non-verbal communication. Still, non-verbal communications could help build the closeness in a parent-child relationship (Dalsgaard et al., 2006). Current means of communication primarily function by exchanging verbal messages that allow people to express concern. Yet literature and this study suggest that regular video and audio methods cannot transmit some non-verbal cues of people's affection, such as the sense of togetherness, memories and some less expressive emotions. This study explored a set of new tools, elements and scenarios to support the situation using non-verbal information as an alternative to the current verbal means.

In general, the study identified three main themes used for family interaction over long distance: Expressing Concern, Emotion and Togetherness/Memory. These dimensions of themes could help to better understand the nature of remote intimate communication between young adult children and older parents. In the meantime, it enables us to identify the inability of digital communications to convey intimate meaning, which might be carried by particular artifacts found in daily life. These findings identified the gap in ways of current interaction. That could encourage designers to benefit from the use of memorable objects, and to explore potential new interaction tools that are able to convey richer types of information.

\section{(3) To augment the behavior of parents and children through a sensorial interface for} engaging in remote intimate experiences, designers need to shift focus from screenbased interfaces to a wider range of sensorial interfaces. 
The concepts for envisioned interactive tools explored in this study provide insights into developing sensorial interfaces that could augment remote intimate experiences between older parents and young adult children. The findings led to an understanding of some elements and features for designing potential interactive objects. This study argues that context adaptability and non-screen based forms should be the new features that future interfaces are required to have for remote intimate communication.

Context adaptability reflects on the form of wearable tools. Combining general context of ubiquitous computing and intimate computing, this study verifies wearable computing as an effective form for intimate interaction and enhancing the extent of intimacy between people and technology, as well as person-to-person relationships. Wearable objects are context-adaptable due to their portability and intimate properties that allow two remote people to connect to each other without time or location constraints. Furthermore, wearable objects can be passive forms to enhance technological abilities (Picard, 1997; Picard \& Klein, 2002; Paiva, 2000), to detect affect, and to exchange emotional information by sensing body motion or heart rate.

Integrating both the findings of the present study and the discussion about the future trend in technology as seen in literature (Weiser, 1999; Mann, 1999; Greenfield, 2010; and Kuang, 2013), the present study proposes moving the interfaces from screenbased to more diverse forms rooted in daily lives. The variations of these forms can support remote communication in two different ways. Firstly, it could provide more types of sensory feedback and personal information that cannot by supplied by current digital communication, and thus, enhance the extent of intimate awareness (Ijsselsteijn \& 
Ridder, 1998; Tollmar et al., 2000; Durlach \& Slater, 1998). For instance, the results identified smell channels are strongly tied to the meaning of memories, family stories, and other personal attachments. Teacups were the potential models for communicating scents. Second, natural gestures rooted in daily activities can be incorporated into new interfaces, not just touching screen and buttons. These features fit into the general trend to create an integrated experience, a smooth hybrid of real world and digital interactions (Kuang, 2013).

\section{(4) Intimate experience needs to be customized through metaphors.}

Intimate experiences are associated with personal stories and memories.

Compared to digital text and graphics, this study indicates that physical artifacts and metaphors that promote personal attachment or identity can more effectively share emotional messages, and are more likely to make people feel connected. The results present some typical physical forms like handwriting, drawing, physical storage of photos and particular scents for communicating intimate experiences, whereas these forms are increasingly replaced by less meaningful digital information. This finding provides the reason to challenge existing digital forms, and augment remote intimacy by integrating technology into personalized artifacts.

On the other side, customization reflects on the asymmetry and symmetry of communication patterns discovered in research. The asymmetry implies that parents and children can interact with different objects in pairs and that the forms could be diverse and based on personal preference. Symmetry interprets the similar features of interfaces and message functions. This interaction process needs to establish certain ground rules to 
code outputs with particular meanings. Coding information is a process to create a personalized language between the two connected people.

\subsection{Limitation of Study}

The limitations of this study resulted from sampling. Due to the time and resource restrictions, the sample size was small. This affected the validity of the quantitative data from the diary study that was not convincing enough to be brought into discussion. In the co-design workshops, the small sample also limited the diversity and creativity of the concepts when developing new interactive tools. To explore more possibilities and creative ideas for new interaction methods, future studies in relevant areas should aim to involve a broader sample of participants. Also, it was unable to recruit enough male parents in this study, thus it was hard to ensure gender balance in the sample population. It is unknown how gender difference would influence the results at this point.

Moreover, the inspirational materials of messages and objects used in the workshops were restricted in forms, which also limited the participants' creativity and possibilities for developing tools. In addition, participants brainstormed the features of the objects and the scenarios based on their personal preference and experiences. The effectiveness in communicating emotional messages in a general group still needs to be verified.

Another limitation is the adaptability and suitability for applying these new means of interaction. This research explores a few user scenarios that might not be suitable for all contexts. Intimate experiences are influenced by cultural/ local background and individual family stories, that may not be shared by a larger group. The metaphors and 
elements explored in this study might have different meanings in different cultural backgrounds. Therefore, to propose these new interactive methods for family communication, designers may need to develop highly customized forms of communication tools associated with personal attachment and preference. There, more user scenarios tied to different cultural backgrounds for intimate interaction need to be investigated. The future interactive tools are also required to be more flexible to fit the context. 


\section{CHAPTER 6. CONCLUSION}

\subsection{Summary}

This research explored sensory emotional communication in distributed family contexts in several different stages. First, the literature review investigated the body of knowledge from diverse disciplines. Based on the framework created from the knowledge, the research questions and methods were shaped for this study. Second, the diary study collected the themes, memorable objects and other associations rooted in everyday lives and family communication activities. The result of the diary study provided the opportunity to inform the co-design workshops with potential design elements and reframe further the research question to explore the possibility of new interactive tools. Then, the co-design workshops developed a set of concepts and artifacts for enhancing remote emotional communication. By analyzing the results of this investigation, the study eventually identified the valuable findings that contribute to the insights for designing new methods for remote communication. It also involved the discussion about the limitation of this study and possible future research direction.

\subsection{Contribution}

This research explores the possibility of breaking away from conventional means of remote communication, and exploring new forms of tools for long distance interaction. It provides alternative possibilities for remote family members to maintain long-distance relationships. Sharing the concepts of ubiquitous computing and intimate computing 
(Weiser, 1999; Bell et al., 1991), the findings of this investigation provide the insight that future means of remote interaction will probably become more connected to daily lives and surrounding environments, allowing people to interact with them more naturally. This trend also supports the notion that the forms of tools will no longer limit the users in front of the screen, whereas they will become more flexible and embedded into people's daily objects.

Particularly, the study proposed wearable, teacups, family photos and other physical objects as interfaces for interaction. Each of them has a unique nature for delivering information and connecting interaction with the flexible context of people's daily lives. The diversity of those interfaces may inspire designers to explore more sensory modalities that are currently missing and relevant future applications.

Furthermore, while many designers are making efforts to develop current technologies to support verbal (video and audio) communication, this study encourages researchers and designers to be more aware of the significance of non-verbal interaction in intimate family scenarios. It is a passive means that supplies the presence of the other person without active verbal connections. In some cases, non-verbal communication might be more adaptable to the situation. The exploration of multi-sensorial interfaces helps to identify some important missing cues that are not translated from face-to-face intimate communications in long-distance connections, such as the sense of smell tied to personal memories and togetherness. These new cues may inspire designers to develop more mature design concepts for non-verbal interaction. Outside of this scope, it could also contribute to some other situations that need non-verbal language to communicate between some special groups, like hearing impaired and speech-impaired people. 
On the other hand, the research explored the different types of information, and attempted to understand the meaning of remote intimate communication. By analyzing how people transmit these important messages, it identified the associated sensory modalities, metaphors and interfaces. The investigation contributes to a better understanding of how well digital and physical objects communicate intimate information.

\subsection{Future work}

This study provides valuable insights for exploring new concepts for remote emotional interaction between family members. Some new applications might appear in the future, however, non-verbal communication and other new forms cannot substitute for those existing verbal means that dominate in people's lives, as well as in-person interaction. They cannot fully supply the channels and emotional cues from in-person communication. Despite that, the development of technologies and related research can still improve intimate emotional experiences between family members over long distances through augmenting sensory feedback. Future work could simulate more natural virtual experiences that are similar to the nature of in-person interaction.

Lastly, the nature of this study is a constructed exploratory method. The researcher did not limit the participants' imagination, but tried to understand the nature and possible direction of their needs. For that reason, some of the ideas that come from the activities are not limited by current technology constraints, however it cannot ignore the feasibility to develop these tools. The sense of smell is one of the special findings from this study. However, existing technology and research put little effort into augmenting smell feedback due to the limitations of simulating scents. This suggests that 
the exploration of this new area has just started, and it still needs to be powered by technological capabilities and innovation. 


\section{BIBLIOGRAPHY}

Abras, C., Maloney-Krichmar, D., \& Preece, J. (2004). User-centered design. Bainbridge, W. Encyclopedia of Human-Computer Interaction. Thousand Oaks: Sage Publications, $37(4), 445-56$.

Ackerman, D. (1990). A natural history of the senses. Random House Digital, Inc.

Adamson, G. (2007). Thinking through craft (Vol. 159). Oxford: Berg.

Babbie, Earl. (2007). The Practice of Social Research. 11th edition. Belmont CA: Thompson - Wadsworth. 87-89.

Bell, G., Brooke, T., Churchill, E., \& Paulos, E. (2003). Intimate ubiquitous computing. In Proc. UbiComp Workshop, 3-6.

Beyer, H., \& Holtzblatt, K. (1998). Contextual design: defining customer-centered systems. Morgan Kaufmann.

Broekens, J., \& Brinkman, W. P. (2013). AffectButton: A method for reliable and valid affective self-report. International Journal of Human-Computer Studies, 71(6), p641-667. doi:10.1016/j.ijhcs.2013.02.003

Bradley, M. M., \& Lang, P. J. (1994). Measuring emotion: the self-assessment manikin and the semantic differential. Journal of behavior therapy and experimental psychiatry, 25(1), 49-59.

Creswell, J. W., Klassen, A. C., Plano Clark, V. L., \& Smith, K. C. (2011). Best practices for mixed methods research in the health sciences. Bethesda (Maryland): National Institutes of Health.

Csikszentmihalyi, M. (1996). Creativity: Flow and the Psychology of Discovery and Invention. Harper Collins.

Chang, A., Resner, B., Koerner, B., Wang, X., \& Ishii, H. (2001). LumiTouch: an emotional communication device. In Conference on Human Factors in Computing Systems: CHI'01 extended abstracts on Human factors in computing systems (31), 313314, Seattle, WA, USA.

Chang, A., \& Ishii, H. (2006). Sensorial interfaces. In Proceedings of the 6th conference on Designing Interactive systems, 50-59. ACM.

Counts, S., \& Fellheimer, E. (2004). Supporting social presence through lightweight photo sharing on and off the desktop. In Proceedings of the SIGCHI conference on Human factors in computing systems, 599-606. ACM. 
Creswell, J. W. (2009). Research design: Qualitative, quantitative, and mixed methods approaches. Sage Publications, Incorporated, California.

Dib, L., Petrelli, D., \& Whittaker, S. (2010). Sonic souvenirs: exploring the paradoxes of recorded sound for family remembering. In Proceedings of the 2010 ACM conference on Computer supported cooperative work, 391-400. ACM.

Dalsgaard, T., Skov, M. B., Stougaard, M., \& Thomassen, B. (2006). Mediated intimacy in families: understanding the relation between children and parents. In Proceedings of the 2006 conference on Interaction design and children, 145-152. ACM.

Dalsgaard, T., Skov, M. B., \& Thomassen, B. R. (2007). eKISS: sharing experiences in families through a picture blog. In Proceedings of the 21st British HCI Group Annual Conference on People and Computers: HCI... but not as we know it-Volume 1, 67-75. British Computer Society.

Decrop, A. (1999). Triangulation in qualitative tourism research. Tourism management, 20(1), 157-161.

Ekman, P. (1993). Facial expression and emotion. American Psychologist, 48(4), 384392.

Frijda, N. H. \& Mesquita, B., (1991). The various effects of emotion communication. Paper presented at the sixth meeting of the international Society for Research on emotion 1991(July), Saarbrucken, Germany.

Frohlich, D., \& Murphy, R. (2000). The memory box. Personal Technologies, 4(4), 238240.

Gaver, B., Dunne, T., \& Pacenti, E. (1999). Design: cultural probes. Interactions, 6(1), 21-29.

Greenfield, A. (2010). Everyware: The dawning age of ubiquitous computing. New Riders, Berkeley, US.

Girouard, A., Tarun, A., \& Vertegaal, R. (2012, May). DisplayStacks: interaction techniques for stacks of flexible thin-film displays. In Proceedings of the 2012 ACM annual conference on Human Factors in Computing Systems, 2431-2440, ACM.

Grivas, K. (2006). Digital Selves: Devices for intimate communications between homes. Personal and Ubiquitous Computing, 10(2-3), 66-76.

Greene, J. C., Caracelli, V. J., \& Graham, W. F. (1989). Toward a conceptual framework for mixed-method evaluation designs. Educational evaluation and policy analysis, 11(3), 255-274. 
Habib, R., \& Khan, A. (2007). Easing the communication: the electronic letter. In Scandinavian Student Interaction Design Research Conference, 50.

Holman, D., \& Vertegaal, R. (2008). Organic user interfaces: designing computers in any way, shape, or form. Communications of the ACM, 51(6), 48-55.

Hopper, R., Knapp, M. L., \& Scott, L. (1981). Couples’ personal idioms: Exploring intimate talk. Journal of Communication, 31(1), 23-33.

Hanington, B. (2012). Universal Methods of Design: 100 Ways to Research Complex Problems, Develop Innovative Ideas, and Design Effective Solutions. Rockport

Publishers, Beverly, US.

Ishii, H., Mazalek, A., \& Lee, J. (2001). Bottles as a minimal interface to access digital information. In CHI'01 extended abstracts on Human factors in computing systems, 187188. ACM.

Johnson, R. B., Onwuegbuzie, A. J., \& Turner, L. A. (2007). Toward a definition of mixed methods research. Journal of mixed methods research, 1(2), 112-133.

Kennedy, T. L., Smith, A., Wells, A. T., \& Wellman, B. (2008). Networked families. Pew Internet \& American Life Project, 1-44.

Kolko, J. (2010). Exposing the Magic of Design: A Practitioner's Guide to the Methods and Theory of Synthesis. Oxford University Press, New York.

Krippendorff, K. (2005). The semantic turn: A new foundation for design. CRC Press, Boca Raton, FL.

Kuang, C. (2013, August 13). Like magic_ Why a new golden age for UI Design is around the corner. Wired. Retrieved September 20, 2013, http://www.wired.com/design/2013/08/design-and-the-digital-world/

Kobrin, F. E. (1976). The primary individual and the family: Changes in living arrangements in the United States since 1940. Journal of Marriage and the Family, 233239.

Lahey, B., Girouard, A., Burleson, W., \& Vertegaal, R. (2011). PaperPhone: understanding the use of bend gestures in mobile devices with flexible electronic paper displays. In Proceedings of the SIGCHI Conference on Human Factors in Computing Systems, 1303-1312. ACM.

Mann, S. (1998). Definition of Wearable Computer. Retrieved Jun12, 2012, from http://wearcomp.org/wearcompdef.html 
Miner, C. S., Chan, D. M., \& Campbell, C. (2001). Digital jewelry: wearable technology for everyday life. In CHI'01 Extended Abstracts on Human Factors in Computing Systems, 45-46. ACM.

Mattelmaki, T. (2006). Design probes. Ph.D. thesis, The University of Art and Design Helsinki.

Planalp, S. (1999). Communicating emotion: Social, moral, and cultural processes. Cambridge University Press, Cambrdge, UK.

Planalp, S., \& Knie, K. (2002). Integrating verbal and nonverbal emotion (al) messages. The verbal communication of emotions: interdisciplinary perspectives, 55-79.

Picard, R. W., \& Healey, J. (1997). Affective wearables. Personal Technologies, 1(4), $231-240$.

Picard, R. W., \& Klein, J. (2002). Computers that recognize and respond to user emotion: theoretical and practical implications. Interacting with Computers, 14(2), 141-169.

Riordan, M. a., \& Kreuz, R. J. (2010). Cues in computer-mediated communication: A corpus analysis. Computers in Human Behavior, 26(6), 1806-1817.

Rice, R. E. (1993). Media appropriateness. Human communication research, 19(4), 451484.

Stebbins, R. A. (Ed.). (2001). Exploratory research in the social sciences (Vol. 48). 3, Sage.

Sieber, S. D. (1973). The integration of fieldwork and survey methods. American journal of sociology, 1335-1359.

Sanders, E. B. N., \& Stappers, P. J. (2008). Co-creation and the new landscapes of design. Co-design, 4(1), 5-18.

Sanders, E. B., \& Stappers, P. J. (2012). Convivial toolbox. Generative Research for the front end of design, 6-58.

Sawyer, R. K. (2006). Explaining creativity: The science of human innovation. Oxford University Press, New York.

Smith, J., \& MacLean, K. (2007). Communicating emotion through a haptic link: Design space and methodology. International Journal of Human-Computer Studies, 65(4), 376387. doi:10.1016/j.ijhcs.2006.11.006

Sallnäs, E. L. (1999). Presence in multimodal interfaces. In Proceedings of the 2nd International Conference on Presence, 6-7. 
Siio, I., Rowan, J., \& Mynatt, E. (2002). Peek-a-drawer: communication by furniture. In CHI'02 extended abstracts on Human factors in computing systems, 582-583. ACM.

Samani, H. A., Parsani, R., Rodriguez, L. T., Saadatian, E., Dissanayake, K. H., \& Cheok, A. D. (2012). Kissenger: design of a kiss transmission device. In Proceedings of the Designing Interactive Systems Conference, 48-57. ACM.

Schifferstein, H. N. (2011). Multi sensory design. In Procedings of the Second Conference on Creativity and Innovation in Design, 361-362. ACM.

Suk, H., \& Design, I. (2009). Emotional Response to a Picture by the Change of Color : a comparison study between adults and children. Design \& Emotion: Theoretical issues, (82), 1-19.

Seymour, S. (2008). Fashionable technology: the intersection of design, fashion, science, and technology. Springer Vien: New York.

Sternberg, R. J., \& Lubart, T. I. (1995). Defying the crowd: Cultivating creativity in a culture of conformity. Free Press, New York.

Tollmar, K., Junestrand, S., \& Torgny, O. (2000). Virtually Living Together_A Design Framework for New Communication Media. DIS '00 Proceedings of the 3rd conference on Designing interactive systems: processes, practices, methods, and techniques, 83-91.

Tollmar, K., \& Persson, J. (2002). Understanding remote presence. In Proceedings of the second Nordic conference on Human-computer interaction (pp.41-50). ACM.

Teh, J. K. S., Cheok, A. D., Choi, Y., Fernando, C. L., Peiris, R. L., \& Fernando, O. N. N. (2009). Huggy pajama: a parent and child hugging communication system. In Proceedings of the 8th International Conference on Interaction Design and Children, 290291. ACM.

Vetere, F, et al. (2005). Mediating intimacy: designing technologies to support strong-tie relationships. In Proceedings of the SIGCHI conference on Human factors in computing systems, 471-480. ACM.

Watson, D., Clark, L. A., \& Tellegen, A. (1988). Development and Validation of Brief Measures of Positive and Negative Affect: The PANAS Scales. Journal of Personality and Social Psychology, 54(6), 1063-1070.

Wallace, J., Thieme, A., Wood, G., Schofield, G., \& Olivier, P. (2012). Enabling self, intimacy and a sense of home in dementia: An enquiry into design in a hospital setting. In Proceedings of the SIGCHI Conference on Human Factors in Computing Systems, 26292638. ACM.

Walther, J. B., \& D'Addario, K. P. (2001). The impacts of emoticons on message 
interpretation in computer-mediated communication. Social Science Computer Review, 19(3) 324-347.

Werner, J., \& Hornecker, E. (2008). United-Pulse : Feeling Your Partner 's Pulse. MobileHCI, Amsterdam, 535-538.

Weiser, M. (1999). The computer for the 21st century. ACM SIGMOBILE mobile computing and communications review, 3(3), 3-11.

Westerlund, B., Lindqvist, S., Mackay, W., \& Sundblad, Y. (2003). Co-design methods for designing with and for families. In proceedings for 5th European Academy of Design Conference 2003, 1-10, Barcelona.

Willis, M. J., \& Jones, C. M. (2012). Emotishare: supporting emotion communication through ubiquitous technologies. In Proceedings of the 24th Australian Computer-Human Interaction Conference, 657-660. ACM.

Witmer, B. G., \& Singer, M. J. (1998). Measuring presence in virtual environments: A presence questionnaire. Presence: Teleoperators and virtual environments, 7(3), 225-240.

Wong-Villacres, M., \& Bardzell, S. (2011). Technology-mediated parent-child intimacy: designing for ecuadorian families separated by migration. In CHI'11 Extended Abstracts on Human Factors in Computing Systems, 2215-2220. ACM.

Yarosh, S., Cuzzort, S., Müller, H., \& Abowd, G. D. (2009). Developing a media space for remote synchronous parent-child interaction. In Proceedings of the 8th International Conference on Interaction Design and Children, 97-105, ACM.

Zuckerman, O., \& Maes, P. (2005, January). Awareness system for children in distributed families. In interaction design for children. 


\section{APPENDIX A. Diary study questionnaire}

\section{SAMPLE OF DIARY QUESTIONNAIRE}

\section{Introduction}

Thank you for taking the time to participate in my study, it won't take long! Please record your daily communication activities that are associated with keeping in touch with your parents/children and objects you used or saw in use during the day in this journal. Also, you need to complete several short exercises below.

Icons for writing $\left[\mathbb{\square}\right.$, camera $\boldsymbol{\sigma}^{\circ}$, and drawing will appear throughout the questionnaire so you get an idea about what to input in the journal -some writing, a drawing, or a photo!

- Name:

- Age:

- Gender: $\mathrm{F} \square / \mathrm{M}$

- Children $\square \quad$ Parent $\square$

- What do you do?

- Where do you live?

- Where do your parents/children live?

- How familiar with technology you are?

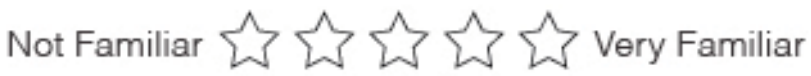

- How comfortable with technology you are?

Not Comfortable 


\section{No.1 Communication activities:}

Date (exact or approximated):

Communication object(s):

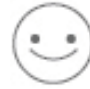

Agreeing with the following statement: Note: use the stars as a scale of your feelings, one line for each option.

No stars $=$ completely disagree

5 stars $=$ I completely agree

"I felt when we communicated."

"I felt to use the device/tools."

Happy

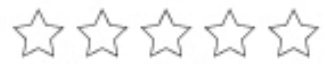

Connected

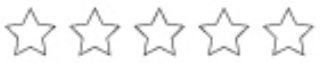

Easy

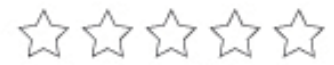

Frustrated

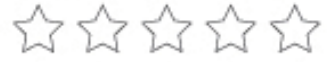

Flowing

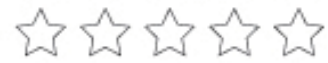

Lonely

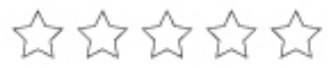

Uneasy

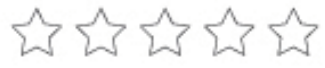

Other

There are 2 identical pages here for you to use. Please record 2 instances of your communication activities with your parents/children within a specific week, using 1 page for each communication. If you contact your parents/children frequently, you may record three instances of what happened during this week. If you are unable to contact your family three times in this one week, you may recall your most recent experiences.

How do you communicate with your parents/ children?

I use (e.g. device, software or app).

Place:

Duration:

Descibe your communication processes and steps how do you interact with the device or software:

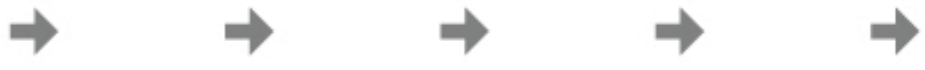

List the significant moments during your communication activity: (what was the essence of your communication e.g. said hello, reported a concern, asked for something. etc.)

1.

2. 


\section{Emotional expressions}

What type of emotional expression would you prefer to use often in your communication with your parent/ children? Use the colored pencil to select five of them, and use the blank space to write down each one of the 5 means to you.

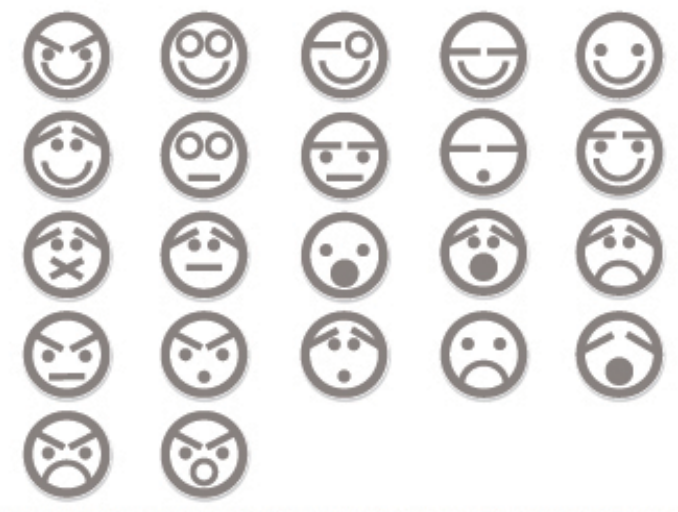

\section{No.1 Memorable objects}

Here are my most memorable artifacts (any objects, e.g. meaningful gift, photo) that are associated with my children/parents, insert a photo here or draw them, and use a few words to describe:

Name of the object:

Describe it:

Appearance (e.g. form, colour, material, character)?

Why this specific object is memorable, and how does it associate with your family?

How do you interact with it (e.g. play, use)?

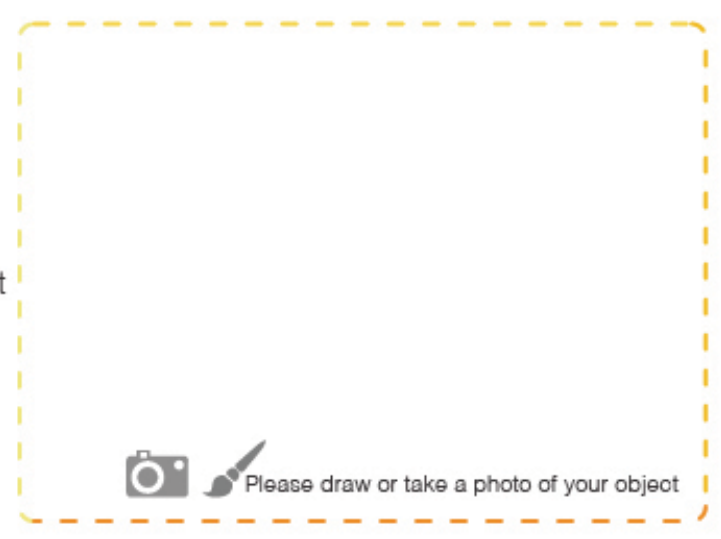

\section{$10^{\circ}$ Imagination exercise:}

List 4 symbolic things that you could accociate with familial affection or a sense of family. They could be any abstract or concrete things or words (e.g. warm, baby carriage, house, etc.). You may either use words, draw sketches or take photos to describe:

1.

3.
2.

4. 


\section{APPENDIX B. The results of Emotional expressions exercise}

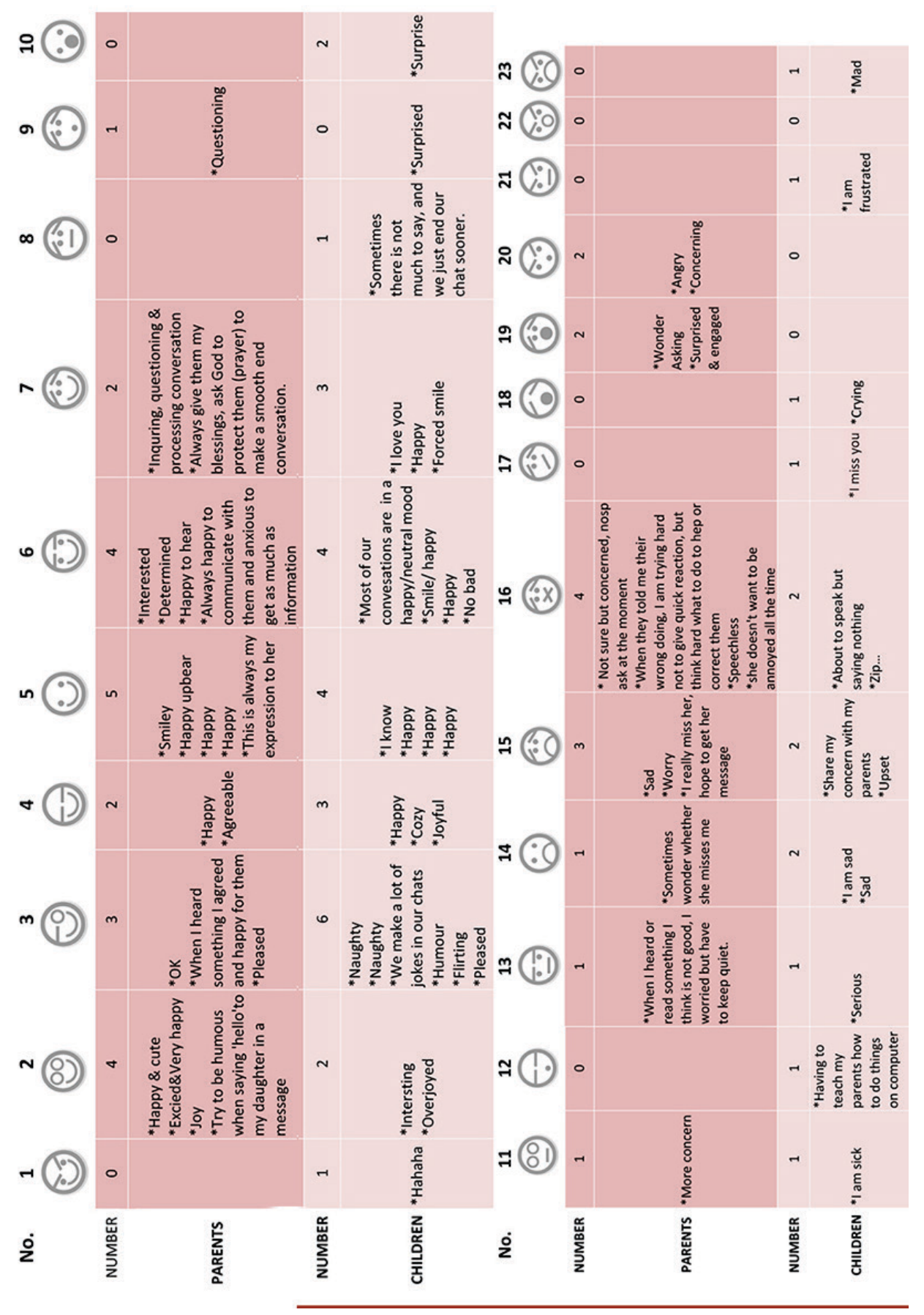

Table 18. The numbers and interpretations of emotional expressions 


\section{APPENDIX C. Workshop}

\section{WORKSHOP BRIEFING SCRIPT}

\section{Introduction:}

Hi everyone, welcome to this workshop. I'm Ariel. I hope you all will enjoy this relaxed and playful session together. First, I must thank all of you who have participated in the diary study, which helped us to generate the materials for this workshop. As some of you may know, my study explores how smart objects can be used for communication between older parents and young adult children who live far apart, like in different cities or even different countries. In this workshop we hope to explore some ideas for creating objects that would work for you in connecting with your family members who are far away. We will be doing a few short exercises in pairs. The whole workshop will take about $1.5-2 \mathrm{hrs}$. Before we begin, we do need to ask you to sign a consent form. There are 2 copies of this form here, please sign both and return only 1 to me, and keep the other one for your information.

\section{Schedule:}

This session includes 3 sections and everyone will be divided into a group of two people. Firstly, we will take 20mins to play a card sorting game. Then, we will ask you to explore the remote communication scenarios between parents and children. Based on the scenario described in this session, you and your teammate will be designing a prototype of the imaginary objects with the toolkit we provide. At the end, each group will present their ideas and works.

\section{Exercise1_Introduction:}

The first exercise is a card sorting game; we would like you as a group to identify what type of messages is most important to you when communicating with your children or parents.

1. Each card contains a message idea about what you might want to communicate, such as I miss you, or how was your day?

2. First of all, try to sort them into different categories and give those categories names. For example if we had cards with the words animals, or party, or food they may all go into a category that you decide to call Daily News

3. Then try to rank most likely messages within each category

4. Then try to prioritize these categories. Discuss which categories would be the most important ones to share with your family member who is far away.

5. Please share your thinking with the larger group. (Each pair will explain their thinking and others may discuss them \& the differences between the way they organized their cards).

Set up notes: hand out message cards and start excercise1 ...... also hand out an instruction sheet so they can refer to it.

\section{Introduction2:}


According to our research, parents and children use the following ways to communicate such as phone, Skype, Email and Instant Messaging. While these technologies can keep us in touch with one another to some extent, they can be complicated to use in comparison with the way we would communicate in person. That's why we are interested in exploring new ways for staying on touch.

Technology:

Current technologies have been greatly developed enabling us to explore new ways to communicate messages. The term "wearable technologies" may not be familiar to you, but it is already in our daily lives. For example maybe you wear a heart rate monitor when exercising or a pedometer when walking, or you know someone who does. These are examples of simple wearable technologies that use computer chips or sensors to add smart functions or new features. The objects I mentioned are very functional, but we are wondering if by applying new technologies to some of the meaningful and memorable objects in our daily lives, we could transform them into different kinds of interactive communication tools. Maybe they could be constantly sending and receiving emotions, experiences, or messages of some sort.

\section{Input and Output:}

To design such smart and interactive objects, we need to understand two important elements: input and output. A simple example of this is a light switch- when you turn on the switch (which is your input) the light goes on (which is the output that results from your input) and when you turn it off (which is your input again) the light goes off (which is the resulting output). In every case where there is input it involves some sort of stimuli or signals, which a person initiates. In every case where there is some sort of output it involves some response that can be seen, felt, touched, heard, and smelled, or some other obvious change of state.

Showing some physical examples- turning on/off a flashlight

Showing some examples on slides:

*Origin Inputs: Person: touch, turn on/off, motion, sound, proximity, Stretch

Environment: light, humidity, sound, temperature

*Sense Outputs: Visual LEDs, color, shape, vibration, display, sound speakers

Set up notes: hand out cards, an assortment of materials and instruction sheets for the excercise2.

\section{Exercise 2:}

We would like to ask your team to pretend that you have a magic object that can connect you with your family member who is far away. Each team can choose one or more object cards that represent an object that you can imagine having in your house, which would somehow be an object you would like to be able to use to connect with your family member. The object you choose has to be something you agree would be an object you or your family member would want or already have in your homes.

We are asking you to pretend at this point that your object will have some magical features that will enable you to connect in some way with your distant family member to communicate the messages you already indicated were important when you sorted the 
cards in the previous exercise. Any ideas are good ideas, this is a playful exercise, and does not have to be realistic.

For example, if I wanted to ask my mother how to cook eggplant I could imagine myself opening the fridge door and putting the eggplant on a magic tray and know that my mother would see it on the picture frame on her fridge door. That would be my input. The output here is that she sees a picture of the eggplant. Then she could send me a recipe that my fridge would print- that would be her input, which is also output at my end. If I take the eggplant off the tray (which would be my input), she would see I received her recipe because a smile would show up on her fridge door picture frame.

Pretend that your object can have input at both ends and output at both ends that somehow enables you to send messages to one another in a way that does not use words. Try to identify 2 or 3 kinds of magic properties that would enable you to share the important messages or categories of messages you identified in the previous exercise. You need to decide what the special functions the object may have are, and what are the inputs and outputs in this way of communicating, in terms of what would people do with the object and how would they see and feel.

You will have 10-15 minutes to decide on an object and figure out what you want it to do.

Then we want you to use the supplies provided to make a rough model of the object or objects. You will have another 10 minutes to make your objects, making sure you include the input and output features.

After you have an idea about the ways your object or objects will enable you to send and receive messages with your family member, please plan to act out how it could work. You can act it out by playing the imaginary roles, or you can sketch pictures of the step by step ways that you see this working, or you can make a chart to show us how it would work. Or a combination of these ways to get across how it would work. You will have another 10 minutes to plan how to let us know what the inputs and outputs are and how this object would fit into your and your family member's homes.

Finally your team will have 5 minutes to act out or explain how it works to the rest of us. In the end everyone can discuss which of the imaginary scenarios would interest them.

\section{Debriefing}

Prop Kits:

Paper \& paperboard Markers \& Color pencils

Plasticine Pipe cleaners

Message Cards Object Cards

Gloves Teacups

Mini flashlights Tags

Glue \& masking tape Scissors 


\section{INSTRUCTION SHEET I (20mins) Excercise1}

Requirements: Identify what type of messages is most important to you when communicating with your children or parents.

Steps:

(1) Sort cards in different categories and give those categories names (5mins)

(2) Rank most likely messages within each category (5mins)

(3) Prioritize these categories. Discuss which categories would be the most important ones to share with your family who is far away (5mins).

(4) Share your ideas with everybody. Explain why you organized the cards into these categories and what you decided were the most important ones. (5mins, 2-3mins for each group)

\section{INSTRUCTION SHEET II (40mins)}

\section{Excercise2}

Requirements:

* Choose two objects from the cards (they can be the same object or different one) that represent an object that you could have in your house, which would somehow be the object you would like to be able to use to connect with your family members.

* Identify 2 or 3 kinds of magical properties that would enable you to share the important messages or categories of messages you identified in the previous exercise.

* Choose your inputs and outputs. Outputs could be 1-3 graphic symbols (i.e. smile) and physical that represents your message (i.e. Inputs: touch, turn on/off, motion, sound, proximity, stretch, light, humidity, sound, temperature; Outputs: Light, color, shape, vibration, display. sound speakers and others)

Steps:

(1) Discussion: decide what the special functions the object/objects may have, what message you want to deliver and what are the inputs/outputs in this way of communicating (10mins).

(2) Use the supplies provided to make rough model(s) of the object(s), making sure you include the input and output features (10mins).

(3) Act out how it could work: Playing the imaginary roles, or sketching a number of cartoon-like pictures that can demonstrate a step by step workflow, or making a chart to show how would it work, or a combination of these ways (10mins).

(4) Presentation: show your model(s), act out or explain how it works (5mins for each group). 


\section{APPENDIX D. Ethics Documentation}

\section{CONSENT FORM}

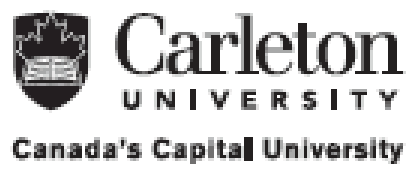

\section{Examining sensorial interfaces as the stimuli for remote affective communication}

$\mathrm{I}$, , agree to participate in a program of research being conducted by Xinchu Zhang, a student in the Masters of Design Program at Carleton University. (Email:

\section{Purpose and Task Requirements:}

The purpose of this study is to learn about how family members communicate affection over distance using interactive wearable devices, to explore new design opportunities.

- Participants will be asked to record their communication activities in a diary for 1 week.

- Participants will meet with researcher and other participants and join them in a 2 hours exploratory focus group/workshop.

In each session, participants will be asked to fill in provided journals, and to take pictures with cameras that will be provided, and leave them with the researcher.

I agree to have my dairy recorded...yes no

I agree to have my workshop session video -taped...yes no

Potential Risk and Benefit: There are no physical or psychological risks in this study. If you feel anxious and/or uncomfortable in any way about your involvement in this study, please bring your concerns to the researcher's attention.

The benefits of this participation are, your contribution to a design for improving people's remote communication experience with their family members, and you will also receive a $\$ 10$ Starbucks gift card for your participation.

Anonymity/Confidentiality: The data collected in this observation are confidential. All data are coded such that your name is not associated with the data. The coded data will only be available to the researchers involved in this study. The electronic data will be stored in a secure external 
hard drive for approximately one year. Anonymous data may be used in future related projects. Research findings will be made available to participants upon request.

Right to Withdraw: Your participation in this study is entirely voluntary. At any point during the study, you have the right to not answer certain questions. Also, you can back out of the study or request your private information be destroyed immediately if unusual or uncomfortable circumstances arise. If circumstances do not allow you to complete the diary for the requested one-week time frame, you may complete the survey for a different one-week time frame.

This project has been reviewed and received ethics approval and clearance by

Research Ethics Coordinator

Leslie MacDonald-Hicks

Carleton University Research Office

Carleton University

1125 Colonel By Drive

Ottawa, Ontario K1S 5B6

Tel: 613: 520-2517

Email: leslie_macdonald-hicks@carleton.ca

I have read the above information and voluntarily consent to participate in the study as described above.

Signature of participant Date

Signature of Researcher Date

If at any time you have questions about your rights as a research participant, please contact the Carleton University, Associate Professor Lois Frankel and Assistant Professor Audrey Girouard, by email at lois_frankel@carleton.ca/Audrey_girouard@carleton.ca.

Note: Sign two copies. One is for the participant and one is for the research records. 